\title{
Non-GAAP EPS Denominator Choices
}

\author{
Kurt H. Gee* \\ Penn State University \\ kurthgee@psu.edu \\ Thomas J. Linsmeier \\ University of Wisconsin-Madison \\ thomas.linsmeier@wisc.edu \\ Clay Partridge \\ University of California-Davis \\ cpartridge@ucdavis.edu
}

August 2021

*Corresponding author: 354 Business Building, University Park, PA 16802. We appreciate helpful comments from Derek Christensen, Michael Durney, Bret Johnson, Henry Laurion, An-Ping Lin (AAA Annual Meeting Discussant), Paul Munter, Jed Neilson, Cathy Shakespeare, Dan Wangerin, Zac Wiebe, Ben Whipple, and workshop participants at Penn State University. 


\title{
Non-GAAP EPS Denominator Choices
}

\begin{abstract}
We provide the first comprehensive evidence about firms' non-GAAP EPS denominator choices. SEC guidance requires firms to report non-GAAP EPS "on a diluted basis". 14 percent of nonGAAP EPS reporting firms adjust the GAAP diluted EPS denominator; 56 percent of loss converting firms (reporting GAAP loss and non-GAAP profit) adjust the GAAP denominator. Nearly all adjustments (1) increase the denominator by adding potential claims, (2) reduce nonGAAP EPS, and (3) increase non-GAAP EPS informativeness incrementally to that of numerator adjustments. Opportunism in denominator choices is concentrated in loss converting firms that fail to adjust the denominator and, instead, use the GAAP diluted EPS denominator which excludes all potential claims. In this instance, non-GAAP EPS is more likely to exceed the EPS number analysts consider appropriate. Overall, we find that nearly all adjusted denominators are informative and convey information about potential claims, which underscores the importance of such claims for investors.
\end{abstract}




\section{Introduction}

This study examines the number of shares that firms use for the denominator of non-GAAP earnings per share (EPS) and whether these denominator choices provide useful information to investors. Firms increasingly report non-GAAP earnings to investors (typically GAAP earnings excluding certain expenses) and do so on an explicit per share basis (Bentley, Christensen, Gee, and Whipple 2018). In Regulation G, which governs non-GAAP financial measures, SEC (2003) requires firms to provide non-GAAP per share measures “on a diluted basis". Diluted EPS conveys information about both (1) earnings available to common shareholders and (2) the number of potential claims on that income, which investors need to assess their potential future returns. The SEC's requirement is consistent with denominator choices and communication of potential claims being important for non-GAAP financial measures.

In an early examination of non-GAAP reporting, Bhattacharya, Black, Christensen, and Larson (2003) document how firms calculate non-GAAP EPS and find that adjustments related to the denominator of non-GAAP EPS are the third most common adjustment (27 percent of observations in their sample), behind depreciation or amortization (36 percent) and stock-based compensation expense (30 percent). Bhattacharya et al. (2003) conjecture that denominator adjustments are opportunistic and provide initial limited evidence suggesting that analysts' forecast revisions are more likely to discount non-GAAP EPS of firms that make denominator adjustments. Bradshaw (2003, p. 328) notes that denominator adjustments: “... seem to be a purely manipulative disclosure practice and given the high frequency of such adjustments in the sample, further analysis is clearly warranted." Despite the relatively high proportion of denominator adjustments in Bhattacharya et al. (2003), the academic literature has provided no additional evidence on denominator choices; 
studies focus almost exclusively on motivations for adjusting earnings, the non-GAAP EPS numerator.

In the nearly two decades of research, the non-GAAP literature provides increasing evidence that, on average, non-GAAP reporting is informative to investors with opportunistic reporting practices concentrated in specific settings (Doyle, Jennings and Soliman 2013: Chen, Chiu, Shevlin, and Wang 2020; Laurion and Sloan 2020; Campbell, Gee, and Wiebe 2021). Non-GAAP EPS denominator choices could reflect opportunism, particularly if firms adjust denominators to inflate non-GAAP EPS. Alternatively, denominator choices could represent firms informing investors about the potential effects of dilutive instruments (e.g., stock-based compensation and convertible instruments) on firms' claims. Prior literature on GAAP EPS identifies deficiencies in how GAAP determines the number of shares to include in diluted EPS and finds that GAAP misrepresents potential claims (Core, Guay, and Kothari 2002; Partridge 2021). Firms' denominator choices for non-GAAP EPS could mitigate these deficiencies and, therefore, improve the usefulness of EPS for investors.

Fourteen percent of our sample of non-GAAP EPS reporting firms use a different denominator than that of GAAP diluted EPS, with substantial variation in denominator choices being observed for firms reporting GAAP and non-GAAP earnings of opposite signs (e.g., GAAP loss and nonGAAP profit). More than 50 percent of firms adjust the denominator when reporting either a GAAP loss and non-GAAP profit (loss converting firms, hereafter) or a GAAP profit and nonGAAP loss. In contrast, fewer than 7 percent of firms adjust the denominator when reporting both a GAAP and non-GAAP loss or GAAP and non-GAAP profit (profit-profit firms, hereafter). Firms adjusting the denominator have both higher analyst following and higher litigation risk and are less likely to miss earnings benchmarks on a GAAP basis. This is consistent with firms facing 
greater scrutiny choosing to make denominator adjustments for reasons other than benchmark beating.

We develop predictions regarding how three denominator choices could reflect informative or opportunistic motives: (1) increase shares in GAAP diluted EPS denominator, or (2) decrease shares in GAAP diluted EPS denominator, or (3) make no adjustment to shares in GAAP diluted EPS denominator. We test these predictions separately for two sets of firms for which we have sufficient sample size: loss converting firms and profit-profit firms.

We define informative denominator choices as those that improve investors' understanding of potential claims. Diluted EPS provides investors with a measure of the number of future common shares that could be issued related to share-based compensation, convertible debt, preferred stock, and/or warrants. Core et al. (2002) provide evidence that GAAP underrepresents the diluted number of shares relative to economic theory for profitable firms issuing employee stock options. For firms reporting GAAP losses, GAAP diluted EPS also underrepresents potential claims by excluding all potential claims from the calculation of the denominator. For both loss converting firms and profit-profit firms, we predict that an informative adjustment increases the denominator to add additional shares and reduces underrepresentation of potential claims; such an adjustment would also decrease non-GAAP EPS. ${ }^{1}$ We find that $56 \%$ of loss converting firms and $4 \%$ of profitprofit firms report in this manner and increase the number of shares in the non-GAAP EPS denominator as compared to the GAAP diluted EPS denominator.

\footnotetext{
${ }^{1}$ Profitable GAAP firms with convertible instruments in their capital structure (e.g., convertible debt) use the ifconverted method to calculate diluted EPS. Partridge (2021) finds that for profitable firms with convertible instruments, potential claims can be either under- or overrepresented, depending on the context. Given certain complexities in the calculation of diluted EPS for these firms (see section 2.1), we exclude GAAP profitable firms with convertible instruments from much of our analyses, such that we predict that GAAP generally underrepresents the number of claims relative to economic theory for firms in our sample.
} 
We expect that such denominator increasing adjustments improve the usefulness of non-GAAP EPS and provide evidence that confirms that expectation. We find, for both loss converting and profit-profit firms, that non-GAAP EPS denominator increasing adjustments (1) significantly reduce GAAP's underrepresentation of potential future claims and (2) increase the explanatory power of non-GAAP EPS for stock prices when compared to both GAAP diluted EPS and nonGAAP diluted EPS with numerator adjustments only. These findings are consistent with denominator increasing adjustments being informative.

We define opportunistic denominator choices as those that inhibit investors' understanding of potential claims. For both loss converting firms and profit-profit firms, we predict that a denominator decreasing adjustment is opportunistic because it (1) exacerbates underrepresentation of potential claims and (2) increases non-GAAP EPS. Despite the concerns about opportunistic denominator choices noted in early non-GAAP research, we find that almost no firms make denominator decreasing adjustments. Fewer than $1 \%$ of loss converting or profit-profit firms adjust the denominator to reduce the shares relative to that in GAAP diluted EPS. This evidence taken together with the frequency and nature of the share increasing adjustments suggests that nearly all denominator adjustments observed in firms reporting non-GAAP EPS are informative.

One remaining potential opportunistic denominator choice available to loss converting firms is tied to guidance in Regulation G (SEC 2003). Regulation G, Footnote 49, requires that firms reporting non-GAAP EPS do so "on a diluted basis", unless failing to do so would comply with GAAP and not be misleading in the context of other information provided (SEC 2003). While the guidance does not specify what accompanying information could make a denominator choice misleading, one such situation may arise when firms report profitable non-GAAP EPS in the presence of a GAAP EPS loss. GAAP requires that diluted EPS exclude all potential claims when 
firms report a loss. When loss converting firms report a GAAP loss but a non-GAAP profit, firms could add potential claims to the denominator of profitable non-GAAP EPS. Alternatively, a loss converting firm could choose to use (and not adjust) the GAAP diluted EPS denominator that omits potential claims. This choice might comply with SEC guidance to report "on a diluted basis" because it uses the GAAP diluted EPS denominator. However, it could also be opportunistic because the firm reports a non-GAAP profit and fails to include potential claims that are reported under GAAP for profitable firms, which yields a metric that is potentially misleading when taken together with accompanying information. Nearly half of loss converting firms report non-GAAP EPS in this manner: using the GAAP diluted loss per share denominator despite reporting a nonGAAP profit. At least some of these firms may choose the denominator opportunistically to inflate non-GAAP EPS by excluding potential claims.

We perform three tests to understand why these loss converting firms do not adjust denominators. First, to determine whether there are material potential claims to adjust, we examine stock-based compensation disclosures and find evidence of potential claims that would add shares to the denominator when performing the EPS calculation. Second, we find that loss converting firms that fail to adjust the EPS denominator are significantly more likely to miss analysts' forecasts on both a GAAP basis and a street basis, which creates incentives for them to resort to aggressive non-GAAP reporting to improve investors' perceptions.

Third, we examine whether analysts consider the EPS of non-adjusting loss converters to be inflated. Consistent with prior research, we compare firm's non-GAAP EPS to its I/B/E/S actual street EPS to provide evidence about whether analysts adjust for or ignore less informative nonGAAP reporting choices (Bentley et al. 2018). We find that non-denominator-adjusting loss converters are nearly three times as likely to report non-GAAP EPS that exceeds I/B/E/S actual 
street EPS, and twice as likely to meet or beat I/B/E/S street earnings benchmarks they would otherwise miss. Together, these findings suggest that while non-adjusting loss converters could be interpreting their denominator choice as being consistent with SEC guidance, at least some of firms may be doing so for opportunistic reasons. Our findings imply that for loss converting firms, potential opportunism is concentrated in the lack of a denominator adjustment, rather than the presence of one, similar to firms' failure to report non-GAAP earnings in the presence of a onetime gain (Curtis, McVay, and Whipple 2014).

Our research makes three academic contributions. First, we contribute to academic research related to non-GAAP reporting. We provide the first comprehensive examination of motivations for non-GAAP denominator choices. Early studies in non-GAAP reporting note the existence of denominator adjustments and provide limited initial evidence that presumes that these adjustments are intended to mislead investors by increasing EPS (Bhattacharya et al. 2003; Bradshaw 2003). In contrast, we find almost no evidence that firms make denominator adjustments for such reasons. Although denominator adjustments have the potential to be a low-cost way to inflate non-GAAP EPS, we document that nearly all denominator adjustments in recent periods decrease non-GAAP EPS and are informative in nature. Finally, we provide evidence that opportunistic objectives are achieved by some loss converting firms that make the choice not to adjust the denominator, which inflates non-GAAP EPS.

Second, we provide evidence on the importance of potential claims in investors' assessments of their future returns. The diluted EPS denominator includes a measure of potential claims to aid investors' assessments of future returns available to current and future shareholders. We find firms that voluntarily adjust the denominator to improve the measurement of potential claims and provide better information for investors. In doing so, we document a new purpose for non-GAAP 
reporting (i.e., improving assessments of potential claims), which is distinct from the purpose illustrated in prior non-GAAP research on numerator adjustments (i.e., improving assessments of core earnings).

Third, we contribute to the GAAP EPS literature. Core et al. (2002) and Partridge (2021) show that for profitable firms the number of shares included in diluted EPS is inconsistent with economic theory. While relatively few profitable firms voluntarily correct for denominator mismeasurement issues in GAAP diluted EPS, those that make such adjustments provide a more useful measure of potential claims than that provided by GAAP. We also extend the GAAP EPS literature to consider denominator mismeasurement for loss firms and find a greater proportion of firms that adjust the number of shares for this measurement deficiency.

Our evidence is relevant to regulators and standard setters. Our findings suggest that when loss converting firms fail to make denominator adjustments, such behavior is consistent with an objective of maximizing EPS, at least for some firms. The SEC may find this evidence useful when evaluating whether additional non-GAAP reporting guidance for loss converting firms is necessary to make the number of dilutive shares in the non-GAAP EPS denominator consistent with a numerator that is profitable. Standard setters also may find useful our evidence that for firms reporting GAAP losses (1) existing guidance underrepresents the number of future residual claims and (2) the decision-usefulness of EPS is improved by incorporating potential claims in the EPS denominator that mimic the denominator required under GAAP for profitable firms.

\section{Background}

\subsection{Diluted EPS and Potential Claims on Earnings}


The value of current common shareholders' future claims on future residual earnings of the firm depends on the number of future common shareholders. Huson, Scott, and Wier (2001) describe this as potential common shareholders participating in the persistent portion of current period earnings. Thus, current common shareholders must share earnings with potential claims from holders of dilutive instruments that exercise, vest, or convert in the future. GAAP diluted EPS attempts to measure the number of potential claims and the effect that they might have on earnings available to common shareholders. Information on the number of potential claims is important as evidenced by (1) the higher value-relevance of diluted EPS than basic EPS (Jennings, LeClere, and Thompson 1997; Balsam and Lipka 1998), (2) analysts and managers generally forecasting EPS on a diluted basis (Gu and Chen 2004; Christensen, Merkley, Tucker and Venkataraman 2011), and (3) the SEC requiring that non-GAAP EPS be provided on a diluted basis unless failing to do so would comply with GAAP and not be misleading in the context of other information provided. ${ }^{2}$

Because SEC (2003) uses GAAP as a benchmark for denominator choices "on a diluted basis", firms' non-GAAP denominator choices relate to the calculation of the GAAP diluted EPS denominator. ${ }^{3}$ Under ASC 260: Earnings Per Share, basic EPS excludes potential claims and is computed by dividing income available to common stockholders by the weighted average number of common shares outstanding. Diluted EPS adjusts basic EPS to reflect potential claims that

\footnotetext{
2 "...[R] egistrants should consider whether the use of any per share measure that is not calculated using a share figure that is presented on a diluted basis complies with (1) the requirement of Regulation G that a registrant, or a person acting on its behalf, shall not make public a non-GAAP financial measure that, taken together with the information accompanying that measure, contains an untrue statement of a material fact or omits to state a material fact necessary in order to make the presentation of the non-GAAP financial measure, in light of the circumstances under which it is presented, not misleading; and (2) generally accepted accounting principles (see, for example, FASB Statement No. 128, Earnings Per Share)." https://www.sec.gov/rules/final/33-8176.htm

${ }^{3}$ The SEC guidance "on a diluted basis" can be interpreted in multiple ways and leads to diverse reporting practices for denominator choices. Based on recent conversations with SEC staff, the SEC is aware of this diversity but has not reached an official position on it.
} 
would arise if securities or other contracts to issue common stock are exercised, converted, or otherwise result in the issuance of common stock.

How potential claims are reflected in GAAP diluted EPS depends on whether a firm reports GAAP income or a loss. GAAP prohibits firms reporting a loss from reflecting potential claims when calculating diluted EPS because doing so would reduce the loss on a per share basis. Thus, for GAAP loss firms, the denominator of GAAP diluted EPS underrepresents potential claims on earnings. When reporting a GAAP profit, the measurement of potential claims in diluted EPS depends on the form of the instrument. Firms that have stock-based compensation (SBC hereafter), other equity options, or warrants, use the treasury stock method to reflect potential claims when calculating diluted EPS. Core et al. (2002) argue that, for these firms, the denominator of diluted GAAP EPS underrepresents potential claims, and diluted EPS is too high relative to economic theory. Profitable GAAP firms with convertible instruments in their capital structure (e.g., convertible debt) use the if-converted method to calculate diluted EPS. The denominator of profitable firms using the if-converted method in our analyses also generally underrepresent potential claims in diluted EPS, although in other contexts the if-converted method can overrepresent potential claims. ${ }^{4}$

\subsection{Hypothesis Development}

Prior research on non-GAAP reporting finds evidence consistent with both informative and opportunistic non-GAAP reporting choices. Recent evidence of opportunism includes firms

\footnotetext{
${ }^{4}$ Application of the if-converted method considers the effects of both (1) interest expense and/or preferred stock dividends on convertible instruments that are added back to the basic EPS numerator, and (2) the potential number of shares issuable upon conversion that are added to the basic EPS denominator. Partridge (2021) finds that for firms with convertible instruments, potential claims can be under- or over-represented, depending on the context. In most of our analyses in the paper, we exclude profitable GAAP firms with convertible instruments to avoid this complexity.
} 
excluding recurring expenses from the numerator of non-GAAP EPS to meet or beat benchmarks (Doyle et al. 2013), strategically calculating the tax effects of excluded expenses to maximize nonGAAP earnings (Chen et al. 2020), failure by firms to forecast exclusions (Laurion and Sloan (2020) and individually tailored revenue recognition practices (Campbell et al. 2021). ${ }^{5}$ Recent evidence of informative motivation for non-GAAP reporting includes firms converting a GAAP loss into non-GAAP profit when GAAP earnings is a poor predictor of future performance (Leung and Veenman 2018), and firms disclosing non-GAAP EPS more prominently when non-GAAP reporting is of higher quality (Chen, Gee, and Neilson 2021). EPS denominator choices, which involve the number of claims on earnings, could be opportunistic (e.g., Bhattacharya et al. 2003) or informative, and understanding when denominator choices reflect which motive is important for investors and regulators.

We define informative denominator choices as those that help investors assess potential claims on earnings. Because GAAP diluted EPS underrepresents potential claims for (1) firms reporting GAAP losses and (2) firms without convertible instruments reporting GAAP profits, informative denominator choices for these firms would add potential claims to the denominator of GAAP diluted EPS. When firms have profitable non-GAAP earnings, adding potential claims to the denominator decreases reported non-GAAP EPS, which suggests that such a choice likely reflects a motive of informing investors. Our first hypothesis is as follows:

$H_{1}$ : Denominator increasing adjustments to the GAAP diluted EPS denominator are informative.

\footnotetext{
${ }^{5}$ Abdel-Meguid, Jennings, Olsen, and Soliman (2021) provide evidence that narcissistic CEOs are more likely to report non-GAAP EPS opportunistically.
} 
We define opportunistic denominator choices as those that hinder investors in assessing potential claims on earnings. For firms reporting GAAP losses and firms without convertible instruments reporting GAAP profits, removing shares from the denominator of GAAP diluted EPS exacerbates the underrepresentation of potential claims. Therefore, opportunistic denominator choices for these firms are those that subtract potential or current claims from the denominator of GAAP diluted EPS. When firms have profitable non-GAAP earnings, subtracting potential claims from the denominator increases reported non-GAAP EPS, which is consistent with such a choice reflecting a motive of inflating EPS. The earnings management literature documents that firms incur real costs to manage the EPS denominator. ${ }^{6}$ Because firms use non-GAAP reporting as a substitute for real and accrual earnings management (Black, Christensen, Joo, and Schmardebeck 2016), it is plausible that firms could use non-GAAP denominator adjustments to maximize EPS. Unlike earnings management, denominator adjustments do not incur real costs and do not reverse like accruals. Further, the SEC's acquiescence to diversity in practice could fail to constrain potentially opportunistic choices. Our second hypothesis is as follows:

$H_{2}$ : Denominator decreasing adjustments to the GAAP diluted EPS denominator are opportunistic.

SEC (2003) offers an additional definition of opportunistic denominator choices, based on the criteria that per share measures should not be misleading when taken together with accompanying information and should comply with GAAP. For loss converting firms (reporting both a GAAP loss and non-GAAP profit), GAAP diluted EPS excludes potential claims from the denominator

\footnotetext{
${ }^{6}$ This research finds that the EPS denominator (and dilution in general) is a determinant of capital structure (Graham and Harvey 2001), transaction structuring (Marquardt and Wiedman 2005; Marquardt and Wiedman 2011; Lewis and Verwijmeren 2011), and share repurchases (Bens, Nagar, Skinner, and Wong 2003; Hribar, Jenkins, and Johnson 2006; Myers, Myers, and Skinner 2007).
} 
because the numerator is a loss. However, the firm's non-GAAP reporting changes the numerator to a profit, and profitable firms would include potential claims in the denominator of diluted EPS. The inclusion of potential claims in the denominator of profitable non-GAAP EPS would increase the denominator and reduce non-GAAP EPS. Therefore, loss converting firms that choose not to add potential claims could be doing so opportunistically to avoid decreasing non-GAAP EPS. Alternatively, such firms could believe that using the same denominator as GAAP diluted EPS is compliant with SEC (2003), and not opportunistic, because they report "on a diluted basis". Given that these two potential explanations are equally plausible ex ante, we state our third hypothesis in the null form:

$H_{3}$ : For loss converting firms, using the GAAP diluted EPS denominator is not opportunistic.

Given the paucity of evidence regarding firms' denominator choices, and the potential for firms to strategically choose denominators to mislead, we provide comprehensive evidence on denominator choices and examine their informativeness for investors.

\section{Sample, denominator choice statistics, and determinants}

\subsection{Sample}

We utilize the dataset from Bentley et al. (2018) to identify firms reporting non-GAAP EPS. ${ }^{7}$ Due to the costly nature of hand collection, and our wish to draw inferences related to recent nonGAAP reporting practices, we limit data from Bentley et al. (2018) to firms that announce annual earnings between January 1, 2013, and June 30, 2016 and potentially report annual non-GAAP

\footnotetext{
${ }^{7}$ We thank Jeremy Bentley, Ted Christensen, Kurt Gee, and Ben Whipple for making data publicly available at: https://sites.google.com/view/kurthgee/data.
} 
EPS. Our ending date is the latest date for which non-GAAP EPS data from Bentley et al. (2018) was available when we began collecting data. We require firms to have material dilutive instruments, defined as having at least one penny of SBC per common share outstanding and/or nonzero convertible debt or preferred stock outstanding in Compustat. ${ }^{8}$ We exclude financial firms (SIC 6000-6799) because financial firms often report industry-specific, standardized metrics, such as funds from operations for REITs; GAAP and non-GAAP EPS are likely less important metrics in these industries. Finally, based on hand collection, we exclude firms that do not report annual non-GAAP EPS. Data from Bentley et al. (2018) reflects firms' quarterly non-GAAP EPS disclosures, and, surprisingly, firms with quarterly non-GAAP disclosures EPS do not always report annual non-GAAP EPS. Our final sample consists of 3,027 firm-year observations that report annual non-GAAP EPS (Table 1).

To determine whether the firm makes a non-GAAP EPS denominator adjustment, we compare the non-GAAP denominator to the GAAP diluted EPS denominator and we capture the number of shares adjusted. ${ }^{9,}{ }^{10}$ We use the largest sample with available data for each analysis that follows, which results in different sample sizes for different analyses.

\subsection{Prevalence of Non-GAAP denominator adjustments}

\footnotetext{
${ }^{8}$ Such dilutive instruments are the only source of potential claims that could be included in the denominator of diluted EPS.

${ }^{9}$ We treat any denominator adjustments related to equity warrants (e.g., Barth, Gee, Israeli, and Kasznik 2021) as SBC adjustments because they are accounted for using the treasury stock method.

${ }^{10}$ Hand collection was performed by a combination of RAs and one of the authors. Due to the complicated nature of the hand collection, to test accuracy we randomly selected (1) 30 observations that we identified as having a nonGAAP numerator adjustment related to SBC or convertible instruments, (2) 30 observations that we identified as having a denominator adjustment, and (3) 30 observations that we identified as not reporting non-GAAP EPS. Our hand-collection procedures correctly identify the presence (amount) of non-GAAP numerator adjustments for 90 (87) out of 90 observations. Our hand-collection procedures correctly identify the presence (amount) of non-GAAP denominator adjustments for 87 (86) out of 90 observations. Overall, the data validation procedures generally support the accuracy of the hand-collected data.
} 
Table 2 presents statistics on the prevalence of non-GAAP denominator adjustments. 14 percent of the observations in our sample use a denominator for non-GAAP EPS that differs from that of GAAP diluted EPS. ${ }^{11}$ Panel B of Table 2 shows the proportion of adjustments by FamaFrench 17 industry. The frequency of denominator adjustments ranges from zero percent in Mining and Mineral industry to 20 percent in the Machinery and Business Equipment industry.

When we examine adjustment choices separately by the sign of GAAP and non-GAAP EPS, we find that denominator adjustments are more common when GAAP and non-GAAP EPS are of opposite signs. Loss converting firms exhibit the highest proportion of denominator adjustments; slightly more than half of such firms use a different denominator for GAAP diluted EPS than for non-GAAP EPS. Profit-profit firms exhibit the second largest number of adjusted denominators, even though the proportion relative to the number of firms is small ( 7 percent). Firms reporting a loss on both a GAAP and non-GAAP basis adjust the denominator approximately 5 percent of the time. It is rare for firms to report GAAP profit and non-GAAP loss (13 observations total), but when doing so, firms adjust the denominator nearly 50 percent of the time.

\subsection{Determinants of Non-GAAP Denominator Adjustments}

Univariate descriptive statistics suggest that oppositely signed GAAP and non-GAAP earnings is an important determinant of denominator adjustments. To understand other potential determinants of denominator choices, we estimate Equation 1 using a probit model.

\footnotetext{
${ }^{11}$ Untabulated statistics reveal that all denominator adjustments are accompanied by some sort of numerator adjustment (i.e., exclusions); no firms in our sample adjust only the denominator to achieve a non-GAAP EPS number.
} 


$$
\begin{aligned}
D E N O M_{-} A D J_{i, t}= & \beta_{0}+\beta_{1} E A R N_{-} S I G N_{-} D I F F_{i, t}+\beta_{2} T R A N S_{-} I T E M_{i, t}+ \\
& \beta_{3} S I Z E_{i, t}+\beta_{4} \text { BM }_{i, t}+\beta_{5} S T D R O A_{i, t}+\beta_{6} N_{-} \text {ANALYSTS } S_{i, t}+ \\
& \beta_{7} \text { LIT_RISK }_{i, t}+\beta_{8} N E G_{-} F E_{-} G A A P_{i, t}+\text { Industry FEs }+\epsilon_{i, t}
\end{aligned}
$$

$E A R N \_S I G N \_D I F F$ is an indicator variable equal to one if the sign of GAAP and non-GAAP earnings differ (e.g., a GAAP loss and non-GAAP profit) and zero otherwise. The remaining variables are common to determinants models of non-GAAP reporting. TRANS_ITEM is an indicator variable equal to one if Compustat identifies transitory items in GAAP earnings. Prior research finds that the presence of transitory items is a determinant of non-GAAP reporting because firms tend to exclude such items. SIZE is a proxy for firm size based on total assets. $B M$, the book-to-market ratio, is a proxy for growth opportunities. STDROA is a measure of the volatility of earnings. $N \_A N A L Y S T S$ is a count of the number of analysts contributing to the consensus street EPS forecast and is a proxy for scrutiny by market participants. LIT_RISK is an annual measure of ex-ante litigation risk (following Kim and Skinner 2012). NEG_FE_GAAP is an indicator variable equal to one if the firm misses earnings expectations on a GAP basis and zero otherwise. Firms that miss analyst expectations on a GAAP basis have incentives to use nonGAAP reporting choices to improve perceptions of performance. All variables are defined in more detail in Appendix 1. Because Table 2 shows variation in denominator adjustments by industry, we include industry fixed effects based on Fama-French 17 industries. In Equation 1 and other equations that follow, we cluster standard errors by firm.

Table 3, Panel A presents descriptive statistics for the variables used in the determinants model. Of the observations with sufficient data to calculate regression variables, $13 \%$ adjust the denominator, and $14 \%$ have opposite signs of earnings for GAAP and non-GAAP EPS. We standardize SIZE, BM, STDROA, and LIT_RISK to have mean of zero and standard deviation of 1 , 
to facilitate interpreting coefficients and marginal effects. The regression model in Column 1 of Panel B includes only EARN_SIGN_DIFF as an independent variable while Column 2 includes all other potential determinants. In Column 1, the marginal effect of EARN_SIGN_DIFF is 0.50. In Column 2, the marginal effect of EARN_SIGN_DIFF is 0.49 , which indicates that having opposite signs of GAAP and non-GAAP EPS is associated with a 49 percent increase in the probability of denominator adjustments. The coefficients on $N \_$ANALYSTS and LIT_RISK are significantly positive (marginal effects of less than 1 percent and 2 percent, respectively), which is consistent with firms adjusting the denominator when they face greater scrutiny. The coefficient on $N E G \_F E \_G A A P$ is significantly negative, which is inconsistent with firms adjusting the denominator when they have incentives to engage in benchmark beating behavior.

Overall, the results in Table 3 suggest that differences in the sign of GAAP and non-GAAP earnings is a primary and economically significant determinant of denominator adjustments. In addition, evidence is inconsistent with firms adjusting denominators to engage in opportunistic behavior.

\section{Tests of Hypotheses}

To test our hypotheses, we focus our analyses on the two groups of firms for which we have sufficient sample size: (1) loss converting firms, which have received particular attention in the non-GAAP literature, and (2) profit-profit firms, which relate most closely to the GAAP EPS literature that examines deficiencies in measuring potential claims. We limit profit-profit firms to those without convertible instruments (i.e., SBC-only firms) for the reasons discussed in section 2.1. Table 4, Panel A presents our predictions for whether denominator choices are informative or opportunistic. Panel B presents descriptive evidence regarding the number of firms making each denominator choice. We find that nearly all denominator adjustments by these groups of firms 
increase the denominator (240/242 for loss converting firms, 76/90 for profit-profit firms), and that few firms decrease the denominator (2/242 and 14/90, respectively).

Example 1 in Appendix 2 illustrates the denominator adjustment of a loss converting firm. Verifone Systems, Inc. increases the denominator when calculating non-GAAP EPS to “...include additional shares that are dilutive, because [it] ha[s] a non-GAAP net income and GAAP basis net loss." Example 2 in Appendix 2 illustrates the denominator adjustment of a profit-profit firm, Ruckus Wireless, Inc., which increases the denominator when calculating non-GAAP EPS (no reason is provided). We predict that these denominator increasing adjustments reflect informative motives $\left(\mathrm{H}_{1}\right)$.

\subsection{Tests of Hypothesis 1}

\subsubsection{Research design}

We examine the informativeness of denominator increasing adjustments in two ways. First, we test whether the adjustments significantly reduce underrepresentation of potential claims. Though all these adjustments increase the denominator, it is unclear ex ante whether the increase is sufficiently large to significantly impact the measurement of potential claims. We predict that denominator increasing adjustments are informative to the extent they help investors assess potential claims; a significant reduction in underrepresentation of claims is a necessary condition for the adjustments to be informative.

We define GAAP_CLAIMS_DIFF (NG_CLAIMS_DIFF), as the difference between potential new claims reflected in the GAAP (non-GAAP) EPS denominator in year $t$ and actual changes in common shares outstanding in year $t+1, t+2$, or $t+3$. We calculate GAAP_CLAIMS_DIFF in year $t$ based on claims in year $t+y$ as: 


$$
G A P_{-} C L A I M S_{-} D I F F_{i, t}=\frac{\left(\frac{c s h f d_{i, t}-c \operatorname{sepri} i_{i, t}}{\text { ajex }_{i, t}}\right)-\left(\frac{c s h o_{i, t+y}}{\text { ajex }_{i, t+y}}-\frac{c s h o_{i, t}}{\text { ajex }_{i, t}}\right)}{\frac{c \operatorname{csho} o_{i, t}}{\text { ajex }_{i, t}}}
$$

The variable cshpri is the number of shares in the denominator of basic EPS in Compustat, and cshfd is the number of shares in the denominator of GAAP diluted EPS in Compustat. The difference (cshfd-cshpri) in Equation 2a reflects the increase in the number of shares as of the end of the period resulting from incorporating potential claims into the denominator of GAAP diluted EPS. The variable csho is the number of shares outstanding in Compustat, and ajex is the adjustment factor in Compustat to account for stock splits.

We calculate $N G \_C L A I M S \_D I F F$ similarly:

$$
N G_{-} C L A I M S_{-} D I F F_{i, t}=\frac{\left(\frac{N G_{-} D E N O M_{i, t}-\operatorname{cshpri}_{i, t}}{\operatorname{ajex}_{i, t}}\right)-\left(\frac{\operatorname{csho}_{i, t+y}}{\operatorname{ajex}_{i, t+y}}-\frac{\operatorname{csho}_{i, t}}{\operatorname{ajex}_{i, t}}\right)}{\frac{\operatorname{csho}_{i, t}}{\operatorname{ajex}_{i, t}}}
$$

$N G \_D E N O M$ is the hand-collected denominator of non-GAAP EPS. The difference $\left(N G_{-} D E N O M-c s h p r i\right)$ reflects the increase in the number of shares as of the end of the period resulting from denominator adjustments.

We consider three important factors in defining these differences. First, by comparing the same firm's GAAP and non-GAAP denominators, we hold constant the effect of any other firm characteristics or events. To the extent firms repurchase or issue shares in the future, this is reflected in future common shares outstanding and our measures provide evidence regarding how the two denominators reflect such changes in claims. Second, we note that $c s h f d$ (or $N G \_D E N O M$ ) in year $t$ and $c s h o$ in year $t+y$ are not directly comparable because the denominator of EPS reflects an average number of shares over the fiscal-year, while csho reflects the number of shares 
outstanding at the end of the fiscal-year. Therefore, we subtract cshpri from the EPS denominator to isolate shares that were added to reflect potential new claims and similarly subtract csho in year $t$ from $c s h o$ in year $t+y$ to isolate actual new claims.

Third, we focus on the signed difference between potential new claims and actual new claims. Based on the Basis for Conclusions of SFAS 128 (paragraphs 93-35), the guidance for diluted EPS was written intentionally to minimize diluted EPS and include more potential claims (FASB 1998). We interpret this as particular concern by standard setters with underrepresentation of potential claims. A negative difference in Equations $2 \mathrm{a}$ or $2 \mathrm{~b}$ signifies a denominator that underrepresents potential claims, and a less negative difference indicates less underrepresentation of potential claims and information that is more decision useful. Unlike analyst forecasts, the horizon for measuring potential claims is unknown, so interpreting a case where potential claims temporarily exceeds actual claims is ambiguous. ${ }^{12}$ Given that prior research finds GAAP underrepresents potential claims, which is based on a signed difference, we examine whether denominator increasing adjustments significantly reduce the underrepresentation.

Our second test of informativeness examines whether the non-GAAP EPS denominator better explains the price of common equity than the GAAP diluted EPS denominator, even with the identical numerator. The price of common equity reflects common shareholders' consensus beliefs of the magnitude and timing of cash flows available to themselves (Barth, Beaver, and Landsman. 2001). Thus, common equity prices reflect investors' beliefs regarding the effect of future claims on current common shareholders' claims on the earnings of the firm. For firms making denominator increasing adjustments, we regress stock price per common share

\footnotetext{
${ }^{12}$ For example, potential claims may overrepresent actual claims one year ahead, but accurately represent claims five years ahead.
} 
(COMMON_PRICE) on EPS measured as either (1) GAAP diluted EPS (EPS_GAAP), (2) nonGAAP EPS numerator divided by the GAAP diluted EPS denominator (EPS_NG_NUM), or (3) non-GAAP EPS (EPS_NG). Price per common share is measured at fiscal year-end so that our analyses reflect the extent to which GAAP and non-GAAP EPS reflect information contemporaneously incorporated into share price. ${ }^{13}$

Our focus is the difference in explanatory power between models based on $E P S \_N G \_N U M$ and $E P S \_N G$, and whether the non-GAAP adjustment to the denominator increases the value relevance of non-GAAP EPS beyond the non-GAAP numerator adjustments. We test for differences in value relevance using the Clarke nonparametric test (Clarke 2003; 2007), which determines which model has better explanatory power for a significant majority of observations. Clarke $(2003,2007)$ finds that this test has greater power than the Vuong (1989) test in identifying which model has better fit, which is why recent research uses this test (e.g., Barth, Gow, and Taylor 2012; Campbell et al. 2021). By comparing three different EPS measures from the same time across the same group of firms, we mitigate issues related to scale effects that could differ cross-sectionally or over time. ${ }^{14}$

\subsubsection{Results for Loss Converting Firms}

Table 5 presents the results of the tests of the informativeness of loss converting firms' denominator increasing adjustments. Panel A presents tests related to the difference in potential and actual claims. We find that the GAAP claims difference is significantly negative for all three time periods, which indicates that the number of shares in the denominator of GAAP diluted EPS

\footnotetext{
${ }^{13}$ All inferences are unchanged when utilizing average stock prices during the week after either the earnings release or the $10-\mathrm{K}$ filing date.

${ }^{14}$ We use tests of the explanatory power, rather than coefficient magnitude, because all denominator adjustments in this test are share-increasing (EPS-decreasing). Thus, the association between COMMON_PRICE and EPS_NG will be mechanically more positive than that for $E P S \_N G \_N U M$ because $E P S \_N G$ is closer to zero, i.e., smaller.
} 
significantly underrepresents the number of future claims. The extent of underrepresentation increases with the horizon over which actual claims are measured. By contrast, we find that the non-GAAP claims difference, which reflects adjustments by the firm, is significantly less negative for all future periods. The adjustments result in a denominator that overrepresents the number of future residual claimants one year ahead, but underrepresents the number of future residual claimants, to a lesser extent than GAAP, two and three years ahead. Overall, these results suggest that the denominator adjustments mitigate the underrepresentation in GAAP of the number of future claims.

Panel B of Table 5 presents tests of the value relevance of non-GAAP EPS for common shareholders. We find that numerator adjustments alone significantly increase the explanatory power of non-GAAP EPS for common share price (p-value from Clarke test $<0.01$, untabulated), which is consistent with prior research that finds that non-GAAP EPS is more related to future operating performance than GAAP EPS. However, we find that incorporating both numerator and denominator adjustments significantly increases the value relevance of non-GAAP EPS for common share price as compared to numerator adjustments alone (p-value from Clarke test < 0.05), though the incremental increase is smaller than that of the numerator adjustments. The Clarke test estimates that price is better explained by $E P S \_N G$ than $E P S \_N G \_N U M$ for approximately 71 percent of the observations (untabulated). Overall, these results are consistent with loss converting firms' non-GAAP denominator adjustments increasing the decisionusefulness of non-GAAP EPS for common shareholders, and therefore consistent with $\mathrm{H}_{1}$.

\subsubsection{Results for Profit-Profit Firms}

Table 6 presents tests of informativeness for SBC-only profit-profit firms that make denominator increasing adjustments. Panel A presents tests related to the difference in potential 
and actual claims. We find that the GAAP claims difference is significantly negative for later periods, which suggests that the number of shares in GAAP EPS significantly underrepresents the number of future residual claimants. However, the difference is not different from zero for oneyear-ahead claims. The non-GAAP claims difference is significantly less negative for one-and two-year-ahead claims, and not significantly different than the GAAP claims difference for later periods.

Panel B of Table 6 presents tests of the value relevance of non-GAAP EPS for common shareholders. We find that incorporating firms' denominator adjustments significantly increases the value relevance of non-GAAP EPS for common share price $(\mathrm{p}$-value from Clarke test $<0.05$ ), which is consistent with these adjustments being relevant for investors, on average. The Clarke test estimates that price is better explained by $E P S \_N G$ than $E P S \_N G \_N U M$ for approximately 83 percent of the observations (untabulated). Overall, we find evidence consistent with profit-profit firms' denominator increasing adjustments improving the decision-usefulness of non-GAAP EPS for common shareholders.

Because nearly all denominator adjustments observed are denominator increasing and evidence in Tables 5 and 6 support the informative nature of these adjustments for both loss converting and profit-profit firms $\left(\mathrm{H}_{1}\right)$, we conclude that nearly all denominator adjustments by firms reporting non-GAAP EPS are informative to investors.

\subsection{Tests of Hypothesis 2}

Because so few firms make denominator decreasing adjustments (16 observations total between loss converting and profit-profit firms, from Table 4, Panel B), we cannot test $\mathrm{H}_{2}$ empirically. Anecdotally, Example 3 of Appendix 2 illustrates a firm making a denominator 
decreasing adjustment. In this example, Total System Services, Inc. reports their non-GAAP metric using the basic EPS denominator rather than the larger diluted EPS denominator. Thus, the firm makes a denominator decreasing adjustment and excludes all potential claims in the nonGAAP denominator. We expect that this denominator adjustment is opportunistic as the firm does not comply with SEC guidance to report "on a diluted basis" and the denominator decreasing adjustment inflates EPS.

\subsection{Tests of Hypothesis 3}

We perform three tests to understand why loss converting firms do not adjust denominators. First, we examine whether such firms have potential claims that could be included in the denominator; if not, the lack of adjustment could be explained by having no adjustment to make. We randomly select 40 loss converting SBC-only firms because identifying potential claims is cleanest under the treasury stock method. Under a GAAP profit, the GAAP diluted EPS denominator calculation includes any in-the-money stock options. ${ }^{15}$ Therefore, we examine whether loss converting firms that choose the GAAP diluted EPS denominator have any in-themoney stock options. We manually examine the stock-based compensation footnote of the 10-K of each firm and find that 39/40 firms (i.e., 97.5\%, untabulated) have in-the-money options or restricted stock, which implies that nearly all non-adjusting loss converting firms have potential claims that are omitted from the denominator of profitable non-GAAP EPS. ${ }^{16}$

\footnotetext{
${ }^{15}$ Restricted stock is equivalent to a stock option with an exercise price of $\$ 0$. Therefore, outstanding restricted stock is always in the money.

${ }^{16}$ Based on financial statement information, we cannot determine the magnitude of the per share impact from including these potential claims in the denominator. However, in untabulated analyses, we find that the GAAP claims difference is significantly negative for these non-adjusting loss converting firms, and not significantly different from the GAAP claims difference of adjusting loss converting firms. Therefore, we conclude that the omitted potential claims are of similar magnitude between non-adjusting and adjusting loss converting firms and thus material to non-adjusting firms.
} 
Our second and third tests are motivated by the assumption that if non-adjusting loss converting firms are merely complying with regulation (i.e., $\mathrm{H}_{3 \mathrm{~B}}$ ), we should not find significant differences between firms that adjust and do not adjust the denominator. For our second test, we examine whether non-adjusting loss converting firms have incentives to inflate non-GAAP EPS by omitting potential claims. We compare non-adjusting loss converting firms that are potentially opportunistic $\left(N O \_D E N O M \_A D J=1\right)$ to loss converting firms that increase the denominator and report informatively $\left(N O \_D E N O M \_A D J=0\right)$. We estimate a modified version of Equation 1 that excludes $E A R N \_S I G N \_D I F F$, because all loss converting firms have sign differences between GAAP and non-GAAP earnings.

Table 7, Panel A presents descriptive statistics for the variables in the determinants model, and Panel B presents results. In Panel B, column 1, we find that non-adjusting firms are significantly more likely to miss analyst expectations on a GAAP basis, which is consistent with having an incentive to use non-GAAP reporting to improve perceptions of performance. To better understand the benchmark beating incentive, we add $N E G_{-} F E \_I B E S$ to the model which is an indicator variable equal to one if $\mathrm{I} / \mathrm{B} / \mathrm{E} / \mathrm{S}$ actual street EPS is less than the street earnings expectation. I/B/E/S street earnings reflects how the majority of analysts follow a firm (Thomson Reuters 2013), is frequently on a non-GAAP basis, and adjusts for or ignores opportunistic non-GAAP reporting (e.g., Bentley et al. 2018). NEG_FE_IBES captures whether informative non-GAAP reporting, based on analysts' street earnings, would miss street earnings benchmarks. In panel B, column 2, we find that non-adjusting firms are significantly more likely to miss expectations on analysts' street basis, which provides further incentive to engage in opportunistic non-GAAP reporting and potentially deviate from analysts. 
For our third test, we examine whether firms' non-GAAP EPS is inflated relative to what analysts consider informative by comparing I/B/E/S actual street EPS and firms' non-GAAP EPS. We measure inflated EPS in two ways: (1) EXCEED, an indicator equal to 1 if firms' non-GAAP EPS is more positive (i.e., exceeds) I/B/E/S street EPS, and equal to 0 otherwise (Kyung, Lee, and Marquardt 2019; Black, Black, Christensen and Gee 2021); and (2) EXCEED_MB, which is equal to 1 if EXCEED equals 1 and the firm's non-GAAP EPS meets or beats the I/B/E/S street EPS forecast while I/B/E/S actual street EPS misses the street EPS forecast, and is equal to 0 otherwise. This latter variable captures whether the firm's non-GAAP reporting choices allow it to claim to meet an earnings benchmark it would otherwise miss.

Table 8 presents statistics for EXCEED and EXCEED_MB depending on whether the firm makes denominator adjustments. Column 1 of Panel A indicates that when a loss converting firm does not make a denominator adjustment, the firm is nearly three times as likely to report a nonGAAP EPS number that exceeds I/B/E/S street EPS (0.37 vs. 0.14). Column 2 of Panel A indicates that firms are twice as likely to exceed and meet or beat the street EPS forecast when not adjusting the denominator (0.14 vs. 0.07). In Panel B, we include controls for exclusion persistence, i.e., whether exclusions relate to transitory items (TRANS_ITEM) or recurring items (RECUR_EXCL), because differences between I/B/E/S EPS and firms' non-GAAP EPS could relate to disagreement regarding the numerator of non-GAAP EPS. Additionally, we add a control variable for the level of analyst coverage (N_ANALYSTS). Results from probit regressions with these controls suggest that when loss converting firms do not adjust the denominator, firms' non-GAAP EPS is significantly more likely to exceed I/B/E/S street EPS and allow the firm to meet or beat the street EPS benchmark. 
Summarizing the results from all three tests, we find that loss-converting firms that use the GAAP diluted EPS denominator (1) omit potential claims that would decrease non-GAAP EPS, (2) have incentives to inflate non-GAAP EPS, and (3) report non-GAAP EPS that analysts believe is too high. Based on these findings, we reject $\mathrm{H}_{3}$ and conclude that at least some non-adjusting loss converting firms make denominator choices opportunistically. While there likely exist some non-adjusting firms that are merely complying and have no opportunistic motive, our results suggest that at least some non-adjusting firms omit potential claims to inflate non-GAAP EPS.

\section{Additional Analyses}

\subsection{How do Firms Increase Denominators?}

Our results in Tables 5 and 6 suggest that denominator increasing adjustments improve the decision-usefulness of non-GAAP EPS. If a standard setter or regulator wanted to require such adjustments for all firms, they would need to know the nature of these adjustments to write precise guidance. There are potentially two ways firms could increase denominators. First, a firm could include the potential claims that GAAP would report if the GAAP diluted EPS guidance were applied to non-GAAP earnings rather than GAAP earnings. Specifically, in calculating the denominator of diluted EPS, a loss converting firm could substitute non-GAAP earnings for GAAP earnings in the calculation but otherwise apply the guidance for profitable firms specified under GAAP (see Verifone in Appendix 2, Example 1).

Second, the firm could deviate from the calculation under GAAP and add different claims than would be required by applying the calculation to non-GAAP earnings. For example, profit-profit firms and loss converting firms could assume all claims result in new shares rather than accounting for potential share repurchases as required under the treasury stock method. Example 4 in 
Appendix 2 illustrates J.G. Wentworth making such an adjustment. J.G. Wentworth uses a nonGAAP EPS denominator that reflects “...the weighted average number of outstanding shares of Class A common stock if all common interests in The J.G. Wentworth Company, LLC were exchanged" (emphasis added). The additional shares are not simply what would be reported under a GAAP profit, but instead include all potential claims and ignore any potential repurchases of shares.

Denominator increasing adjustments by SBC-only profit-profit firms can only occur by including additional claims than those determined by applying GAAP, because applying the GAAP guidance to firms reporting both a GAAP and non-GAAP profit results in the same denominator. However, loss converting firms could make either the first or second type of adjustment, and it therefore is unclear which type of adjustment is responsible for the useful information about potential claims documented in Table 5.

To identify adjustment types for loss converting firms, we hand collect detailed adjustment data for a subsample. We focus this hand collection on identifying the prevalence of firms making the second type of adjustment: adding different claims than would be required by applying the GAAP calculation to non-GAAP earnings. Our best setting to identify such behavior is for SBConly loss converting firms. Under the treasury stock method for calculating diluted EPS, stock options that are out of the money are excluded from the denominator calculation and not considered potential claims because the issuance of additional shares is assumed to be unlikely. Therefore, a firm making denominator increasing adjustments when all options are out of the money must be deviating from the calculation under GAAP by adding more potential claims. Exploiting this fact, SBC-only loss converting firms that include different claims than applying 
the denominator calculation to non-GAAP earnings are most likely to be firms with out-of-themoney options.

We identify the SBC-only loss converting firms with the most out-of-the-money options based on the ratio of stock price at fiscal year-end divided by the average exercise price of exercisable stock options. Firms with a lower ratio are more likely to have out-of-the-money options. We sort firms into quartiles by the price to strike ratio and select up to 30 firms with denominator increasing adjustments from the two quartiles with the lowest ratios. For these selected firms, we read the earnings press release and $10-\mathrm{K}$ to determine the type of denominator increasing adjustment firms make.

Table 9 reports the results of this hand collection. Panel A presents statistics related to the first quartile (i.e., lowest ratios). Only 26 firms in this quartile make denominator increasing adjustments. We find that 21 firms $(80.8 \%)$ apply the GAAP calculation to non-GAAP earnings, i.e., including only the incremental shares that would be present if the firm had reported a GAAP profit. We find only 5 firms $(19.2 \%)$ that add claims differently than applying the GAAP calculation to non-GAAP earnings. Table 9, Panel B, presents statistics related to the second quartile. We find 29 firms (96.7\%) that apply the GAAP calculation to non-GAAP earnings and 1 firm that adds claims different from applying the GAAP calculation to non-GAAP earnings. Given the low prevalence of firms adding claims different from GAAP in the subsamples where we would most expect to find such firms, we conclude that we are unlikely to find this adjustment type if we examined other quartiles. Overall, the vast majority of adjustments for loss converting firms include the potential claims that GAAP would report if the GAAP diluted EPS guidance were applied to profitable non-GAAP earnings. Therefore, we conclude that the increase in the decision- 
usefulness of loss converting firms' non-GAAP EPS results primarily from applying existing GAAP guidance to non-GAAP earnings.

\subsection{Analysts’ Forecast Revisions and Firms’ Denominator Adjustments}

Bhattacharya et al. (2003) conclude that non-GAAP denominator adjustments are opportunistic based on finding that, for firms reporting in 1998-2000, analysts' revisions are significantly less sensitive to firms' non-GAAP earnings when the firms make denominator adjustments (see Table 6 on p. 315 of that paper). To reconcile our findings from a more recent period with those of Bhattacharya et al. (2003), we closely replicate their analysis using annual data for our 2013-2016 sample of firms. We estimate the following equation using OLS:

$$
\begin{aligned}
& \operatorname{REVISION}_{i, t}=\beta_{0}+\beta_{1} F E_{-} N G E P S_{i, t}+\beta_{2} F E_{-} N G E P S_{i, t} \times \\
& D E N O M \_A D J_{i, t}+\beta_{3} D E N O M_{-} A D J_{i, t}+\beta_{4} F E \_N G E P S_{i, t} \times \\
& L O G_{-} M K T C A P_{i, t}+\beta_{5} F E_{-} N G E P S_{i, t} \times L O S S_{-} C N V R T_{i, t}+ \\
& \beta_{6} F E \_N G E P S_{i, t} \times T R A N S_{-} I T E M_{i, t}+ \\
& \beta_{7} L O G_{-} M K T C A P_{i, t}+\beta_{8} L O S S_{-} C N V R T_{i, t}+ \\
& \beta_{9} T R A N S_{-} I T E M_{i, t}+\epsilon
\end{aligned}
$$

REVISION measures analyst forecast revisions for EPS in year $t+1$ that are made after the announcement of earnings in year $t$. FE_NGEPS is defined as the non-GAAP earnings surprise, using the median consensus forecast of I/B/E/S street earnings. DENOM_ADJ is as defined previously and the interaction between $F E \_N G E P S$ and DENOM_ADJ is our variable of interest. We include three variables as controls that are significantly related to forecast revisions in Bhattacharya et al. (2003): market cap (MKTCAP), whether firms report a non-GAAP profit and 
GAAP loss $\left(L O S S \_C N V R T\right)$, and whether firms experience one-time items (TRANS_ITEM).. ${ }^{17}$

Because Bhattacharya et al. (2003) do not separately examine firms based on the sign of GAAP and non-GAAP earnings, we include all non-GAAP reporting firms in our sample in this analysis, including firms reporting both GAAP and non-GAAP losses, firms reporting GAAP profits and non-GAAP losses, and firms with convertible instruments.

Panel A of Table 10 provides descriptive statistics for regression variables. Panel B of Table 10 presents the regression results. In column 1, we find that $F E \_N G E P S$ has a significantly positive association with forecast revisions, consistent with prior research which finds that market participants find non-GAAP reporting informative. In column 2, we find that the coefficient on $F E \_N G E P S \times D E N O M \_A D J$ is not significantly different from zero. In column 3, when we add controls, we find that the coefficient on $F E \_N G E P S \times D E N O M \_A D J$ is positive and marginally significant, in contrast to the significantly negative coefficient in Bhattcharya et al. (2003). Thus, our evidence is inconsistent with denominator adjustments being opportunistic, and instead consistent with most adjustments being informative. ${ }^{18,19}$

\subsection{Converting Non-GAAP EPS into Non-GAAP Earnings}

Because non-GAAP data is more readily available as EPS rather than earnings, studies interested in the properties of non-GAAP earnings typically convert non-GAAP EPS into earnings

\footnotetext{
${ }^{17}$ We construct REVISION, FE_NGEPS, DENOM_ADJ, and LOSS_CNVRT identically to Bhattacharya et al. (2003). MKTCAP is the log of 1 plus the market cap variable in Bhattacharya et al. (2003). TRANS_ITEM differs from the hand collected data on gains and losses from asset sales in Bhattacharya et al. (2003) because we do not have such data. Such items would be categorized as one-time items in Compustat, which is reflected in our TRANS_ITEM variable. Bhattacharya et al. (2003) use quarterly data, while we use annual data.

${ }^{18}$ In untabulated analyses, we estimate Equation 3 for only loss converting firms (SBC-only profit-profit firms), and we find that the coefficient on $F E \_N G E P S \times D E N O M \_A D J$ is not significantly different from zero.

${ }^{19}$ Prior research finds that SEC scrutiny prior to Regulation G (Kolev, Marquardt, and McVay 2008) and Regulation $\mathrm{G}$ itself (Heflin and Hsu 2005) significantly reduced opportunism in non-GAAP reporting. Thus, the differences we find relative to Bhattacharya et al. (2003) could be explained by differences in the regulatory environment between sample periods.
} 
using the GAAP diluted EPS denominator (e.g., Bentley et al. 2018, Chen et al. 2021; Doyle et al. 2003 and Kolev et al. 2008 perform a similar transformation using I/B/E/S street EPS). This method introduces measurement error, particularly for loss converting firms which most commonly use a different denominator. We examine whether this measurement error significantly affects estimates of the persistence of either non-GAAP earnings or non-GAAP exclusions (i.e., GAAP earnings less non-GAAP earnings). We limit this analysis to loss converting firms due to the frequency of their denominator adjustments and because researchers can identify loss converting firms based on existing non-GAAP reporting data.

In untabulated analysis, we regress future operating performance (cash flows and earnings) separately on non-GAAP earnings and non-GAAP exclusions as reported by the firm, and nonGAAP earnings and exclusions approximated using the method in prior research. We find that the measurement error increases the estimated persistence of non-GAAP earnings, but not significantly, and has almost no effect on the estimated persistence of non-GAAP exclusions, which is the primary focus of prior research. Therefore, our analysis suggests that researchers need not be concerned with the practice of approximating non-GAAP earnings using non-GAAP EPS and the GAAP diluted EPS denominator.

\section{Conclusion}

We provide the first evidence on the nature of firms' non-GAAP EPS denominator choices and whether these choices are consistent with informative or opportunistic reporting. Firms' denominator choices in non-GAAP EPS demonstrate the importance of information about potential claims on the earnings of the firm. Firms are most likely to adjust the non-GAAP EPS denominator when reporting opposite signs for GAAP and non-GAAP earnings. Denominator adjustments are nearly always denominator increasing, which mitigates deficiencies in how GAAP 
represents future claims, reduces profitable non-GAAP EPS, and yields EPS measures that are more value relevant. In contrast to opportunistic concerns about denominator adjustments noted in prior literature, we find that denominator adjustments are informative for investors. Opportunistic denominator choices are concentrated in the nearly half of loss converting firms that omit potential claims from the denominator of profitable non-GAAP EPS. Such firms are significantly more likely to report non-GAAP EPS that exceeds analysts' actual street EPS and meet or beat street benchmarks they would otherwise miss.

Our results suggest the potential for regulatory scrutiny by the SEC and clarification to the guidance on reporting non-GAAP EPS “on a diluted basis” (SEC 2003), so that all loss converting firms include potential claims in the denominator. That informative adjustments for loss converting firms most frequently apply the GAAP calculation to non-GAAP earnings may be of interest to standard setters; existing GAAP guidance that adjusts the EPS denominator for potential dilutive claims is useful to investors even in the domain of non-GAAP financial measures. 


\section{References}

Abdel-Meguid, A.H., Jennings, J.N., Olsen, K., and Soliman M.T., 2020. The Impact of the CEO's Personal Narcissism on Non-GAAP Earnings. The Accounting Review, Forthcoming.

Balsam, S., and Lipka, R., 1998. Share prices and alternative measures of earnings per share. Accounting Horizons 12 (3): 234-249.

Barth, M.E., Beaver, W.H., Landsman, W.R., 2001. The relevance of the value relevance literature for financial accounting standard setting: Another view. Journal of Accounting and Economics 31(1), 77-104.

Barth, M.E., Gee, K.H., Israeli, D., Kasznik, R., 2021. Stock Price Management and Share Issuance: Evidence from Equity Warrants. The Accounting Review, Forthcoming.

Barth, M.E., Gow, I.D., Taylor, D.J., 2012. Why do pro forma and street earnings not reflect changes in GAAP? Evidence from SFAS 123R. Review of Accounting Studies 17: 526-562.

Bens, D.A., Nagar, V., Skinner, D.J., and Franco Wong, M.H., 2003. Employee Stock Options, EPS dilution and stock repurchases. Journal of Accounting and Economics 36(1): 51-90.

Bentley, J.W., Christensen, T.E., Gee, K.H., Whipple, B.C., 2018. Disentangling Managers' and Analysts' Non-GAAP Reporting. Journal of Accounting Research 56, 1,039-1,081.

Bhattacharya, N., Black, E.L., Christensen, T.E., Larson, C.R., 2003. Assessing the Relative Informativeness and Permanence of Pro Forma Earnings and GAAP Operating Earnings. Journal of Accounting and Economics 36, 285-319.

Black, D.E., Black, E.L., Christensen, T.E., Gee, K.H., 2021. Comparing Non-GAAP EPS in Earnings Announcements and Proxy Statement. Management Science. Forthcoming.

Black, E.L, Christensen, T.E., Joo, T.T., and Schmardebeck, R., 2016. The Relation Between Earnings Management and Non-GAAP Reporting. Contemporary Accounting Research 34, 750-782.

Bradshaw, M.T., 2003. A discussion of 'Assessing the relative informativeness and permanence of pro forma earnings and GAAP operating earnings.'. Journal of Accounting and Economics 36, 321-335.

Campbell, J.L., Gee, K.H., and Wiebe, Z., 2021. The Determinants and Informativeness of NonGAAP Revenue Disclosures. Working paper, University of Georgia, Penn State, and University of Arkansas.

Chen, N., Chiu, P.C., Shevlin, T., and Wang, J., 2020. Evidence of non-compliance and strategic behavior on tax rates applied to non-GAAP exclusion items. Working paper, University of Houston, Chinese University of Hong Kong, University of California Irvine, and University of International Business and Economics.

Chen, J.V., Gee, K.H., and Nielson, J.J., 2021. Disclosure Prominence and the Quality of Non-GAAP Earnings. Journal of Accounting Research, forthcoming.

Christensen, T.E., Merkley, K.J., Tucker, J.W., Venkataraman, S., 2011. Do managers use earnings guidance to influence street earnings exclusions? Review of Accounting Studies 16, 501-527.

Clarke, K.A., 2003. Nonparametric Model Discrimination in International Relations. Journal of Conflict Resolution 47, 72-93.

Clarke, K.A., 2007. A simple distribution-free test for nonnested model selection. Political Analysis 15, 347-363.

Core, J.E., Guay, W.R., and Kothari, S.P., 2002. The economic dilution of employee stock options: diluted EPS for valuation and financial reporting. The Accounting Review 77, 627-652.

Curtis, A.B., McVay, S.E., and Whipple, B.C. 2014. The disclosure of non-GAAP earnings information in the presence of transitory gains. The Accounting Review, 89(3), 933-958.

Doyle, J.T., Lundholm, R.J., and Soliman, M.T., 2003. The Predictive Value of Expenses Excluded from Pro Forma Earnings. Review of Accounting Studies 8, 145-174. 
Financial Accounting Standards Board (FASB). 1998. Statement of Financial Accounting Standards No. 128, Earnings Per Share. Norwalk, Connecticut.

Graham, J.R., Harvey, C.R., 2001. The theory and practice of corporate finance: evidence from the field. Journal of Financial Economics 60, 187-243.

Gu, Z., Chen, T., 2004. Analysts' treatment of nonrecurring items in street earnings. Journal of Accounting and Economics 38, 129-170.

Heflin, F., and Hsu,C., 2008. The Impact of the SEC's Regulation of Non-GAAP Disclosures. Journal of Accounting and Economics 46, 349-65.

Hribar, P., Jenkins, N.T., Johnson, W.B., 2006. Stock repurchases as an earnings management device. Journal of Accounting and Economics 41, 3-27.

Huson, M.R., Scott, T.W., and Wier, H.A., 2001. Earnings Dilution and the Explanatory Power of Earnings for Returns. The Accounting Review 76(4), 589-612.

Jennings, R., M.J. LeClere, and R.B. Thompson. 1997. Evidence on the usefulness of alternative earnings per share measures. Financial Analysts Journal 53(6): 24-33.

Kim, I., Skinner, D.J. 2012. Measuring Securities Litigation Risk. Journal of Accounting and Economics 53, 290-310.

Kolev. K., Marquardt, C.A., and McVay, S.E., 2008. SEC Scrutiny and the Evolution of Non-GAAP Reporting. The Accounting Review 83, 157-184.

Kyung, H., Lee, H., Marquardt, C., 2019. The effect of voluntary clawback adoption on non-GAAP reporting. Journal of Accounting and Economics 67(1), 175-201.

Laurion, H., and Sloan, R., 2020. When Does Forecasting GAAP Earnings Entail Unreasonable Effort? Working paper, University of Colorado Boulder and University of Southern California.

Leung, E., Veenman, D., 2018. Non-GAAP Earnings Disclosure in Loss Firms. Journal of Accounting Research 56, 1,083-1,137.

Lewis, C. and Verwijmeren, P., 2011. Convertible Security Design and Contract Innovation. Journal of Corporate Finance 17, 809-831.

Marquardt, C., and Wiedman, C., 2005. Earnings Management through Transaction Structuring: Contingent Convertible Debt and Diluted Earnings per Share. Journal of Accounting Research 43(2): 205 - 243.

Marquardt, C., and Wiedman, C., 2011. Disclosure, incentives, and contingently convertible securities. Accounting Horizons 21, 281-294.

Myers, J.N., Myers, L.A., and Skinner, D.J., 2007. Earnings Momentum and Earnings Management. Journal of Accounting, Auditing, and Finance 22, 249-284.

Partridge, C., 2021. The Pricing of Mismeasured EPS. Working paper, University of CaliforniaDavis.

Securities and Exchange Commission (SEC). "Final Rule: Conditions for Use of Non-GAAP Financial Measures," 2003. https://www.sec.gov/rules/final/33-8176.htm

Thomson Reuters.2013. I/B/E/S Summary History. Toronto, Canada.

Vuong, Q.H., 1989. Likelihood ratio tests for model selection and non-nested hypotheses. Econometrica 57, 307-333. 


\section{Appendix 1. Variable Definitions}

\begin{tabular}{|c|c|}
\hline Variable & Description \\
\hline$B M$ & $\begin{array}{l}\text { Book-to-market ratio, calculated as seqq from Compustat divided by } \\
\text { market cap }(|p r c| * \text { shrout }) \text { from CRSP or from Compustat (mkvaltq or } \\
\text { prccq } * \text { cshoq) if missing CRSP data. }\end{array}$ \\
\hline COMMON_PRICE & $\begin{array}{l}\text { Price per share of common equity as of fiscal year-end ( } p r c c \_f \text { from } \\
\text { Compustat). }\end{array}$ \\
\hline DENOM_ADJ & $\begin{array}{l}\text { Indicator set to } 1 \text { if the denominator of non-GAAP EPS differs from that } \\
\text { of GAAP diluted EPS and set to } 0 \text { otherwise. }\end{array}$ \\
\hline$E A R N \_S I G N \_D I F F$ & $\begin{array}{l}\text { Indicator set to } 1 \text { if GAAP EPS and non-GAAP EPS have opposite signs } \\
\text { and set to } 0 \text { otherwise. }\end{array}$ \\
\hline$E P S \_G A A P$ & GAAP diluted EPS (epsfi from Compustat). \\
\hline$E P S \_N G$ & Non-GAAP EPS as reported by the firm. \\
\hline$E P S \_N G \_N U M$ & $\begin{array}{l}\text { The numerator of non-GAAP EPS divided by the number of shares used } \\
\text { in GAAP diluted EPS (cshfd from Compustat). }\end{array}$ \\
\hline EXCEED & $\begin{array}{l}\text { Indicator set to } 1 \text { if the firm's non-GAAP EPS is greater than the } \mathrm{I} / \mathrm{B} / \mathrm{E} / \mathrm{S} \\
\text { actual street EPS for the fiscal year and set to } 0 \text { otherwise. }\end{array}$ \\
\hline EXCEED_MB & $\begin{array}{l}\text { Indicator for whether firms meet or beat I/B/E/S street EPS benchmarks } \\
\text { only because they exceed I/B/E/S actual street EPS. Indicator set to } 1 \text { if } \\
\text { (1) the firm's non-GAAP EPS is greater than the I/B/E/S actual street } \\
\text { EPS (i.e., EXCEED =1), (2) I/B/E/S actual street EPS is less than the } \\
\text { street EPS consensus forecast, and (3) the firm's non-GAAP EPS is } \\
\text { greater than or equal to the I/B/E/S street EPS consensus forecast, and } \\
\text { set to } 0 \text { otherwise. }\end{array}$ \\
\hline$F E \_N G P E S$ & $\begin{array}{l}\text { Non-GAAP earnings surprise, measured as non-GAAP EPS less the } \\
\text { I/B/E/S median consensus street EPS forecast before fiscal year-end, } \\
\text { scaled by stock price as of five trading days before the earnings } \\
\text { announcement. }\end{array}$ \\
\hline \multirow[t]{2}{*}{ GAAP_CLAIMS_DIFF } & $\begin{array}{l}\text { The difference between potential new claims reflected in the GAAP } \\
\text { diluted EPS denominator in year } t \text { and actual new common shares } \\
\text { outstanding in year } t+y \text {. Calculated as: } \\
\qquad\left(\frac{c s h d_{i, t}-\text { cshpri }_{i, t}}{a j e x_{i, t}}\right)-\left(\frac{c s h o_{i, t+y}}{\text { ajex }_{i, t+y}}-\frac{c s h o_{i, t}}{\text { ajex }_{i, t}}\right)\end{array}$ \\
\hline & $\begin{array}{l}\qquad \frac{c s h o_{i, t}}{a j e x_{i, t}} \\
\qquad s h f d \text { is the number of shares in the denominator of GAAP diluted EPS } \\
\text { in Compustat and cshpri is the number of shares in the denominator of } \\
\text { basic EPS in Compustat. The difference (cshfd }-c s h p r i) \text { reflects the } \\
\text { increase in the number of shares as of the end of the period resulting } \\
\text { from incorporating potential claims into the denominator of GAAP } \\
\text { diluted EPS. The variable } c s h o \text { is the number of shares outstanding in } \\
\text { Compustat, and ajex is the adjustment factor in Compustat to account for } \\
\text { stock splits. }\end{array}$ \\
\hline IBES_DIFF & $\begin{array}{l}\text { Indicator set to } 1 \text { if the firm's non-GAAP EPS is different from the } \\
\text { I/B/E/S actual street EPS for the fiscal year and set to } 0 \text { otherwise. }\end{array}$ \\
\hline$L I T \_R I S K$ & $\begin{array}{l}\text { Measure of ex ante litigation risk, using variables and coefficients from } \\
\text { Kim and Skinner (2012), model 3/3a. We merge the litigation risk } \\
\text { measure to our data based on fiscal year. }\end{array}$ \\
\hline
\end{tabular}




\begin{tabular}{|c|c|}
\hline Variable & Description \\
\hline$L O G \_M K T C A P$ & $\begin{array}{l}\text { Natural log of } 1+\text { market cap }(|p r c| * \text { shrout from CRSP divided by } \\
1,000) .\end{array}$ \\
\hline LOSS_CNVRT & $\begin{array}{l}\text { Indicator set to } 1 \text { if the firm reports a GAAP loss per share and a non- } \\
\text { GAAP profit per share and set to } 0 \text { otherwise. }\end{array}$ \\
\hline$N \_A N A L Y S T S$ & $\begin{array}{l}\text { The number of analysts contributing to the } \mathrm{I} / \mathrm{B} / \mathrm{E} / \mathrm{S} \text { street consensus } \\
\text { forecast. }\end{array}$ \\
\hline$N E G \_F E \_G A A P$ & $\begin{array}{l}\text { Indicator set to } 1 \text { if GAAP EPS is less than the I/B/E/S median GAAP } \\
\text { EPS consensus forecast and set to } 0 \text { otherwise. }\end{array}$ \\
\hline$N E G \_F E \_I B E S$ & $\begin{array}{l}\text { Indicator set to } 1 \text { if } \mathrm{I} / \mathrm{B} / \mathrm{E} / \mathrm{S} \text { street EPS is less than the } \mathrm{I} / \mathrm{B} / \mathrm{E} / \mathrm{S} \text { median } \\
\text { street EPS consensus forecast and set to } 0 \text { otherwise. }\end{array}$ \\
\hline \multirow[t]{2}{*}{ NG_CLAIMS_DIFF } & $\begin{array}{l}\text { The difference between potential new claims reflected in the non-GAAP } \\
\text { EPS denominator in year } t \text { and actual new common shares outstanding in } \\
\text { year } t+y \text {. Calculated as: } \\
\qquad\left(\frac{N G_{-} D E N O M_{i, t}-\operatorname{cshpri}_{i, t}}{\text { ajex }_{i, t}}\right)-\left(\frac{\operatorname{csho}_{i, t+y}}{\text { ajex }_{i, t+y}}-\frac{\operatorname{csho}_{i, t}}{\text { ajex }_{i, t}}\right)\end{array}$ \\
\hline & $\begin{array}{l}\qquad \frac{c s h o_{i, t}}{a_{j e x}} \\
N G \_D E N O M \text { is the hand-collected denominator of non-GAAP EPS and } \\
c s h p r i \text { is the number of shares in the denominator of basic EPS in } \\
\text { Compustat. The difference }\left(N G_{-} D E N O M-c s h p r i\right) \text { reflects the } \\
\text { increase in the number of shares as of the end of the period resulting } \\
\text { from denominator adjustments. The variable } c s h o \text { is the number of } \\
\text { shares outstanding in Compustat, and ajex is the adjustment factor in } \\
\text { Compustat to account for stock splits. }\end{array}$ \\
\hline NO_DENOM_ADJ & $\begin{array}{l}\text { Indicator for whether loss converting firms do not adjust the } \\
\text { denominator, relative to loss converting firms that adjust the } \\
\text { denominator in informative ways. Indicator set to } 1 \text { if the firm is a loss } \\
\text { converting firm and DENOM_ADJ=0 and set to } 0 \text { if the firm is a loss } \\
\text { converting firm and (1) DENOM_ADJ }=1 \text {, and (2) the adjustment is } \\
\text { denominator increasing. }\end{array}$ \\
\hline$R E C U R \_E X C L$ & $\begin{array}{l}\text { Indicator set to } 1 \text { if firms exclude recurring items (EPS_NG and oprepsx } \\
\text { from Compustat are different) and set to } 0 \text { otherwise. }\end{array}$ \\
\hline REVISION & $\begin{array}{l}\text { The revision in one-year-ahead street EPS forecasts based on } \\
\text { information in the current annual earnings announcement, calculated } \\
\text { following Bhattacharya et al. (2003). We first calculate the mean } \\
\text { forecast using all year } t+1 \text { forecasts made within the } 60 \text {-day post } \\
\text { announcement window beginning on the year } t \text { earnings announcement } \\
\text { date. We then subtract the mean forecast based on all year } t+1 \text { forecasts } \\
\text { made within a 60-day window immediately prior to the year } t \text { earnings } \\
\text { announcement date. Finally, we scale the forecast revision by the closing } \\
\text { stock price five days before the year } t \text { earnings announcement date. }\end{array}$ \\
\hline SIZE & Natural log of $1+$ total assets (at from Compustat). \\
\hline STDROA & $\begin{array}{l}\text { Standard deviation of ROA (ib/at from Compustat) over at least three of } \\
\text { the previous five years. }\end{array}$ \\
\hline TRANS_ITEM & $\begin{array}{l}\text { Indicator set to } 1 \text { if Compustat identifies a transitory item (epsfi and } \\
\text { opreps } x \text { from Compustat are different) and set to } 0 \text { otherwise. }\end{array}$ \\
\hline
\end{tabular}




\section{Appendix 2. Examples of Non-GAAP Denominator Adjustments}

The presentation of the reconciliation of non-GAAP EPS to GAAP EPS varies greatly across firms. For each example that follows, we construct a simplified table from the information included in the press release to show the GAAP numerator, the GAAP diluted EPS denominator, the non-GAAP numerator, the non-GAAP adjustment to the GAAP diluted EPS denominator, and the non-GAAP denominator. We include a link to the original press release for each example.

\section{Example 1: Denominator increasing adjustment by loss converting firm}

Excerpt from Verifone Systems $4^{\text {th }}$ Quarter 2013 Release $^{20}$

Verifone Systems, Inc.

Reconciliations of Non-GAAP Financial Measures (abridged)

For the Year Ended October 31, 2013

(in millions, except per share data)

\begin{tabular}{|c|c|c|c|}
\hline & GAAP & $\begin{array}{l}\text { Non-GAAP Adjustment } \\
\text { for dilutive shares }\end{array}$ & $\begin{array}{l}\text { Non- } \\
\text { GAAP }\end{array}$ \\
\hline $\begin{array}{l}\text { Net Income (Loss) Attributable to VeriFone } \\
\text { Systems, Inc. stockholders: }\end{array}$ & $\$(296.1)$ & & $\$ 159.7$ \\
\hline $\begin{array}{l}\text { Weighted Average Number of Shares used in } \\
\text { computing net income (loss) per diluted share: }\end{array}$ & 108.6 & $2.3(\mathrm{G})$ & 110.9 \\
\hline $\begin{array}{l}\text { Net income (loss) per share attributable to } \\
\text { VeriFone Systems, Inc. stockholders: }\end{array}$ & $\$(2.73)$ & & $\$ 1.44$ \\
\hline
\end{tabular}

Note G: Non-GAAP diluted shares. During the three and twelve months ended October 31, 2013 and the three months ended July 31, 2013, the diluted non-GAAP weighted average shares include additional shares that are dilutive, because we have a non-GAAP net income and GAAP basis net loss. [Emphasis added.]

\section{Example 2: Denominator increasing adjustment by profit-profit firm}

Excerpt from Ruckus Wireless's $4^{\text {th }}$ Quarter 2014 Press Release ${ }^{21}$

Ruckus Wireless, Inc.

Reconciliation of GAAP to Non-GAAP Financial Measures (abridged)

For the Year Ended December 31, 2014

\footnotetext{
${ }^{20}$ https://www.sec.gov/Archives/edgar/data/1312073/000131207313000046/ex991q42013pressrelease.htm

${ }^{21} \mathrm{https} / / / \mathrm{www} . s e c . g o v / A r c h i v e s / e d g a r / d a t a / 1294016 / 000119312515041613 / \mathrm{d} 869680 \mathrm{dex} 991 . \mathrm{htm}$
} 


$\begin{array}{lccc} & \text { GAAP } & \begin{array}{c}\text { Non-GAAP Adjustment } \\ \text { for dilutive shares }\end{array} & \begin{array}{c}\text { Non- } \\ \text { GAAP }\end{array} \\ \text { Net Income: } & \$ 8,190 & 2,603 & \$ 42,012 \\ \begin{array}{l}\text { Weighted Average Shares used in } \\ \text { calculating diluted net income per share: }\end{array} & 93,668 & 96,271 \\ \text { Diluted net income per share: } & \$ 0.09 & \$ 0.44\end{array}$

Discussion:

GAAP net income is positive, so the diluted EPS denominator includes the GAAP measurement of diluted shares. However, the firm makes an adjustment to further increase the denominator. The firm includes no discussion in the press release for the basis of the non-GAAP adjustment for dilutive shares, which is similar other profit-profit firms making these adjustments.

\section{Example 3: Denominator decreasing adjustment by profit-profit firm}

Excerpt from Total System Services, Inc. 2013 Results Press Release ${ }^{22}$

TSYS

Reconciliation of GAAP to Non-GAAP

Adjusted Cash Earnings

(in thousands, except per share data)

\begin{tabular}{lccc} 
& GAAP & $\begin{array}{c}\text { Non-GAAP Adjustment for } \\
\text { dilutive shares }\end{array}$ & Non-GAAP \\
Cash earnings: & $\$ 244,750$ & $(1,648)$ & $\$ 323,598$ \\
Weighted Average Diluted Shares: & 190,039 & 188,391 \\
\cline { 2 - 3 } Cash EPS: & $\$ 1.29$ & & $\$ 1.72$
\end{tabular}

Discussion:

This firm reports their non-GAAP EPS metric using the basic EPS denominator, rather than the diluted EPS denominator. The firm makes a denominator decreasing adjustment such that the non-GAAP EPS excludes all potential claims. This adjustment appears opportunistic as it does not comply with SEC guidance to report "on a diluted basis" and inflates non-GAAP EPS.

\section{Example 4: Loss converting firm that includes claims beyond the GAAP calculation}

\footnotetext{
${ }^{22}$ https://www.sec.gov/Archives/edgar/data/721683/000119312514024221/d663052dex991.htm
} 
Excerpt from the J.G. Wentworth Company $4^{\text {th }}$ Quarter and Full Year 2015 Results Press Release $^{23}$

The J.G. Wentworth Company

Consolidated Key Metrics Statistics

For the Twelve Months Ended December 31, 2015

(in thousands, except shares and per share data)

\begin{tabular}{lccc} 
& GAAP & $\begin{array}{c}\text { Non-GAAP Adjustment for } \\
\text { dilutive shares }\end{array}$ & Non-GAAP \\
$\begin{array}{lccc}\text { Net Income (Loss) Attributable to } \\
\text { The J.G. Wentworth Company: }\end{array}$ & $\$(95,312)$ & & $\$ 606$ \\
Weighted Average Diluted Shares: & $14,690,746$ & $13,732,270$ & $28,422,016$ \\
\cline { 2 - 4 } Diluted EPS: & $\$(6.49)$ & & $\$ 0.02$
\end{tabular}

Firm Disclosure:

ANI EPS is defined as ANI (Adjusted Net Income) divided by All-in Shares.

All-in Shares: Represents the weighted average number of outstanding shares of Class A common stock if all common interests in The J.G. Wentworth Company, LLC were exchanged. Calculated as the sum of: (a) the weighted average number of Common Interests Outstanding and (b) the impact of dilutive potential common shares. [Emphasis added.]

Discussion:

This is an example of a firm including claims beyond GAAP because the firm includes more shares in the denominator than would be required under the GAAP calculation.

The label "All-in shares" and the description (included above) indicates that the firm is disclosing a measure of non-GAAP EPS that includes all potential claims. To validate this, we examined the prior-year (2014) non-GAAP disclosure when the firm reported a GAAP profit:

The J.G. Wentworth Company

Consolidated Key Metrics Statistics

For the Twelve Months Ended December 31, 2014

(in thousands, except shares and per share data)

Net Income (Loss) Attributable to

GAAP

$\$ 31,211$
Non-GAAP dilutive shares

The J.G. Wentworth Company:

\footnotetext{
${ }^{23}$ https://www.sec.gov/Archives/edgar/data/1580185/000158018516000077/jgw123115exhibit991.htm
} 
Weighted Average Diluted Shares:

$12,988,781$

$16,358,717$

$29,347,498$

Diluted EPS:

$\$ 2.40$

$\$ 1.49$

Discussion:

Since the firm reports a GAAP profit in 2014, the EPS denominator includes the GAAP calculation of potentially dilutive shares related to SBC. Yet, the firm makes a large adjustment to the GAAP denominator when calculating non-GAAP EPS in 2014. This implies that the adjustment observed in 2015 is incremental to applying the GAAP calculation of dilutive shares to non-GAAP earnings. 
Firm-years announcing non-GAAP EPS in at least one fiscal quarter based on $\quad$ 4,546

Bentley et al. (2018) and announcing annual earnings between January 1,

2013 and June 30, 2016

Require at least $\$ 0.01$ per share of stock compensation expense and/or

nonmissing convertible instruments outstanding

Require nonfinancial firms (exclude SIC codes between 6000 and 6799)

Require annual non-GAAP EPS

Final Sample 
Panel A: Statistics for the Sample

All firms $(\mathrm{N}=3,027)$

$\frac{\text { DENOM_ADJ }}{\frac{\mathrm{N}=1}{416} \frac{\text { Mean }}{0.14}}$

Panel B: Statistics by Fama-French 17 Industry

Automobiles $(\mathrm{N}=38)$

\begin{tabular}{rrr}
\multicolumn{2}{c}{ DENOM_ADJ } \\
\cline { 1 - 1 } $\mathbf{N = 1}$ & & Mean \\
\cline { 1 - 1 } 2 & & 0.05 \\
5 & 0.03 \\
5 & 0.07 \\
5 & 0.07 \\
16 & 0.12 \\
1 & 0.04 \\
6 & 0.06
\end{tabular}

Chemicals $(\mathrm{N}=66)$

$122 \quad 0.20$

Machinery and Business Equipment $(\mathrm{N}=612)$

$0 \quad 0.00$

Mining and Minerals $(\mathrm{N}=36)$

$15 \quad 0.10$

Oil and Petroleum Products $(\mathrm{N}=155)$

$25 \quad 0.11$

Retail Stores $(\mathrm{N}=222)$

$3 \quad 0.11$

Textiles, Apparel, and Footware $(\mathrm{N}=47)$

10.02

Transportation $(\mathrm{N}=106)$

$10 \quad 0.09$

Utilities $(\mathrm{N}=99)$

$3 \quad 0.03$

Other $(\mathrm{N}=1,217)$

200

0.16

Panel C: Statistics by the Sign of GAAP and Non-GAAP Earnings

Loss-profit (loss converting) firms $(\mathrm{N}=432)$

\begin{tabular}{|c|c|}
\hline$D E I$ & $A D J$ \\
\hline $\mathbf{N}=\mathbf{1}$ & Mean \\
\hline 242 & 0.56 \\
\hline 150 & 0.07 \\
\hline 18 & 0.05 \\
\hline U & 0.46 \\
\hline
\end{tabular}

This table presents statistics from our hand collection of firms' non-GAAP EPS denominators. DENOM_ADJ indicates that the denominator of non-GAAP EPS differs from that of GAAP diluted EPS. Loss converting firms report a GAAP loss and non-GAAP profit. Profit-profit and loss-loss firms report both GAAP and non-GAAP profit, or loss, respectively. Profit-loss firms report a GAAP profit and non-GAAP loss. 
Table 3: Determinants of Non-GAAP EPS Denominator Choices

Panel A: Descriptive Statistics for Variables in Determinants Model

\begin{tabular}{|c|c|c|c|c|}
\hline Variable & $\mathbf{N}$ & Mean & Median & Std. Dev. \\
\hline DENOM_ADJ & 2,542 & 0.13 & $\overline{0}$ & 0.33 \\
\hline$E A R N \_S I G N \_D I F F$ & 2,542 & 0.14 & 0 & 0.35 \\
\hline TRANS_ITEM & 2,542 & 0.90 & 1 & 0.30 \\
\hline SIZE & 2,542 & 7.66 & 7.59 & 1.66 \\
\hline$B M$ & 2,542 & 0.47 & 0.39 & 0.39 \\
\hline STDROA & 2,542 & 0.06 & 0.03 & 0.07 \\
\hline N_ANALYSTS & 2,542 & 11.93 & 10 & 8.46 \\
\hline$L I T \_R I S K$ & 2,542 & -1.09 & -1.26 & 1.22 \\
\hline$N E G \_F E \_G A A P$ & 2,542 & 0.58 & 1 & 0.49 \\
\hline
\end{tabular}

This table presents determinants of whether firms' make denominator adjustments, based on a probit model. DENOM_ADJ indicates that the denominator of non-GAAP EPS differs from that of GAAP diluted EPS. $E A R N \_S I G N \_D I F F$ indicates whether GAAP and non-GAAP earnings have opposite signs (e.g., GAAP loss and nonGAAP profit). TRANS_ITEM indicates the presence of one-time items in GAAP earnings. LOG_ASSET measures firm assets. $B M$ is the book-to-market ratio. STDROA measures earnings volatility. $N \_A N A L Y S T S$ is the number of analysts following the firm. LIT_RISK measures litigation risk. NEG_FE_GAAP indicates whether the firm misses earnings benchmarks on a GAAP basis. Panel A presents descriptive statistics, and Panel B presents the results. In Panel B, coefficient estimates are presented above standard errors, which are presented in parentheses and clustered by firm. Continuous variables have been standardized to be mean zero and have a variance of one. Estimated marginal effects are presented next to coefficients and calculated as an increase in the probability of the dependent variable when the independent variable changes from zero to one while holding all other independent variables at their mean. Continuous variables are winsorized at the 1st and 99th percentile. All variables are defined in Appendix 1. *, **, and *** indicate a statistically significant difference from zero at the $10 \%, 5 \%$, and $1 \%$ level, respectively. 
Table 3: Determinants of Non-GAAP EPS Denominator Choices (cont.)

Panel B: Determinants Model

\begin{tabular}{|c|c|c|c|}
\hline \multirow[b]{2}{*}{ Variable } & \multicolumn{3}{|c|}{ DENOM_ADJ } \\
\hline & $(1)$ & (2) & \\
\hline Intercept & $\begin{array}{l}-1.605 * * * \\
(0.07)\end{array}$ & & \\
\hline$E A R N \_S I G N \_D I F F$ & $\begin{array}{l}1.749 * * * 0.50 \\
(0.10)\end{array}$ & $\begin{array}{l}1.843 * * * \\
(0.11)\end{array}$ & 0.49 \\
\hline TRANS_ITEM & & $\begin{array}{l}0.112 \\
(0.14)\end{array}$ & 0.01 \\
\hline SIZE & & $\begin{array}{r}-0.042 \\
(0.06)\end{array}$ & -0.01 \\
\hline$B M$ & & $\begin{array}{r}-0.069 \\
(0.06)\end{array}$ & -0.01 \\
\hline STDROA & & $\begin{array}{l}0.054 \\
(0.05)\end{array}$ & 0.01 \\
\hline N_ANALYSTS & & $\begin{array}{l}0.018 * * \\
(0.01)\end{array}$ & 0.00 \\
\hline$L I T \_R I S K$ & & $\begin{array}{l}0.139 * * * \\
(0.04)\end{array}$ & 0.02 \\
\hline$N E G_{-} F E \_G A A P$ & & $\begin{array}{l}-0.203 * * \\
(0.10)\end{array}$ & -0.03 \\
\hline FF17 Industry Fixed Effects & No & Yes & \\
\hline $\mathrm{N}$ & 2,542 & 2,542 & \\
\hline $\mathrm{N}=1$ & 322 & 322 & \\
\hline $\mathrm{N}=0$ & 2,220 & 2,220 & \\
\hline $\mathrm{ROC}$ & 0.7803 & 0.8584 & \\
\hline
\end{tabular}


Table 4: Predicted Reporting Objectives Based on Denominator Choice

Panel A: Predictions

\begin{tabular}{|c|c|c|}
\hline & Loss-Converting Firms & SBC-Only Profit-Profit Firms \\
\hline $\begin{array}{l}\text { No Denominator } \\
\text { Adjustment }\end{array}$ & $\begin{array}{l}\text { Compliant (use GAAP diluted EPS denominator) } \\
\text { or } \\
\text { Opportunistic (exclude potential claims that would be } \\
\text { included under profitable GAAP earnings) }\end{array}$ & Compliant (use GAAP diluted EPS denominator) \\
\hline $\begin{array}{l}\text { Increase } \\
\text { Denominator }\end{array}$ & $\begin{array}{l}\text { Informative (include potential claims, which } \\
\text { decreases non-GAAP EPS) }\end{array}$ & $\begin{array}{l}\text { Informative (include potential claims, which } \\
\text { decreases non-GAAP EPS) }\end{array}$ \\
\hline $\begin{array}{l}\text { Decrease } \\
\text { Denominator }\end{array}$ & $\begin{array}{l}\text { Opportunistic (exclude current claims, which } \\
\text { increases non-GAAP EPS) }\end{array}$ & $\begin{array}{l}\text { Opportunistic (exclude current and/or potential } \\
\text { claims, which increases non-GAAP EPS) }\end{array}$ \\
\hline \multicolumn{3}{|c|}{ : Adjustment Choice Statistics } \\
\hline & $\begin{array}{c}\text { Loss-Converting Firms } \\
\mathrm{N}=432 \\
\end{array}$ & $\begin{array}{c}\text { SBC-Only Profit-Profit Firms } \\
\qquad \mathrm{N}=1,976 \\
\end{array}$ \\
\hline $\begin{array}{l}\text { No Denominator } \\
\text { Adjustment }\end{array}$ & $\mathrm{N}=190(44 \%)$ & $\mathrm{N}=1,886(95 \%)$ \\
\hline Increase & $\mathrm{N}=240(56 \%)$ & $\mathrm{N}=76(4 \%)$ \\
\hline Denominator & Mean (median) EPS impact $=-\$ 0.074(-\$ 0.01)$ & Mean $($ median) EPS impact $=-\$ 0.118(-\$ 0.03)$ \\
\hline $\begin{array}{l}\text { Decrease } \\
\text { Denominator }\end{array}$ & $\begin{array}{l}\mathrm{N}=2(0 \%) \\
\text { Mean }(\text { median }) \text { EPS impact }=\$ 0.025(\$ 0.025)\end{array}$ & $\begin{array}{l}\mathrm{N}=14(1 \%) \\
\text { Mean }(\text { median }) \text { EPS impact }=\$ 0.019(\$ 0.01)\end{array}$ \\
\hline
\end{tabular}

This table relates firms' denominator adjustment choices to predicted reporting objectives (Panel A) and provides statistics on the prevalence of denominator adjustment choices (Panel B). 


\section{Table 5: Testing Informativeness of Loss Converting Firms' Denominator Increasing}

Adjustments

Panel A: Representing Potential Claims

\begin{tabular}{|c|c|c|c|c|}
\hline \multirow[b]{2}{*}{ Time Period } & \multicolumn{2}{|c|}{ GAAP_CLAIMS_DIFF } & \multicolumn{2}{|c|}{$N G \_C L A I M S \_D I F F$} \\
\hline & $\begin{array}{c}1 \\
\text { Mean }\end{array}$ & $\begin{array}{c}2 \\
\text { Median }\end{array}$ & $\begin{array}{c}3 \\
\text { Mean }\end{array}$ & $\begin{array}{c}4 \\
\text { Median }\end{array}$ \\
\hline$\overline{1 \text { Year Ahead }(\mathrm{N}=213)}$ & $-3.5 \% * * *$ & $-2.1 \% * * *$ & $1.4 \% * *$ (a) & $1.1 \% * * *(\mathrm{a})$ \\
\hline 2 Year Ahead $(\mathrm{N}=188)$ & $-7.9 \% * * *$ & $-4.3 \% * * *$ & $-3.1 \% * * *(a)$ & $-1.2 \% * *(a)$ \\
\hline 3 Year Ahead $(\mathrm{N}=164)$ & $-15.6 \% * * *$ & $-7.5 \% * * *$ & $-10.6 \% * * *$ & $-3.3 \% * * *$ (a) \\
\hline
\end{tabular}

Panel B: Value Relevance of EPS

\begin{tabular}{|c|c|c|c|}
\hline Variable & $\begin{array}{c}1 \\
E P S= \\
E P S \_G A A P\end{array}$ & $\begin{array}{c}2 \\
E P S= \\
E P S \_N G \_N U M\end{array}$ & $\begin{array}{c}3 \\
E P S= \\
E P S \_N G\end{array}$ \\
\hline Intercept & $\begin{array}{c}25.135 * * * \\
(2.94)\end{array}$ & $\begin{array}{c}19.000 \text { *** } \\
(2.79)\end{array}$ & $\begin{array}{c}17.773 * * * \\
(2.92)\end{array}$ \\
\hline$E P S$ & $\begin{array}{c}-2.197 * \\
(1.19)\end{array}$ & $\begin{array}{l}9.599 * * * \\
(2.96)\end{array}$ & $\begin{array}{c}11.979 * * * \\
(3.66)\end{array}$ \\
\hline $\mathrm{N}$ & 240 & 240 & 240 \\
\hline Adj. Rsq. & 0.0107 & 0.0874 & 0.1018 (b) \\
\hline
\end{tabular}

This table presents the results of two tests of whether denominator increasing adjustments are informative. The sample in this table consists of loss converting firms with denominator increasing adjustments. Panel A presents statistics on the differences between potential claims reflected in denominators and actual future claims, for GAAP $\left(G A A P \_C L A I M S \_D I F F\right)$ and non-GAAP denominators $\left(N G \_C L A I M S \_D I F F\right)$. Negative values indicate that a denominator underrepresents new future claims. "(a)" in Panel A denotes that the difference between GAAP_CLAIMS_DIFF and NG_CLAIMS_DIFF is statistically significant at the 5\% level, using two-sample t-tests of means or the Wilcoxon rank-sum test. Panel B presents tests of value relevance for the price per share of common equity, COMMON_PRICE, using three different measures of firms' earnings per share. EPS_GAAP is GAAP diluted EPS. $E P S \_N G \_N U M$ is the numerator of non-GAAP EPS divided by the GAAP diluted EPS denominator. $E P S \_N G$ is non-GAAP EPS as reported by the firm. Coefficient estimates are presented above standard errors, which are presented in parentheses and clustered by firm. "(b)" in Panel B denotes that the difference in the explanatory power of the model in Column 3 and that in Column 2 is statistically significant at the 5\% level, based on the Clarke test. Continuous variables are winsorized at the 1 st and 99th percentile. All variables are defined in Appendix 1. *,**, and $* * *$ indicate a statistically significant difference from zero at the $10 \%, 5 \%$, and $1 \%$ level, respectively. 
Table 6: Testing Informativeness of Profit-Profit Firms' Denominator Increasing Adjustments

Panel A: Representing Potential Claims

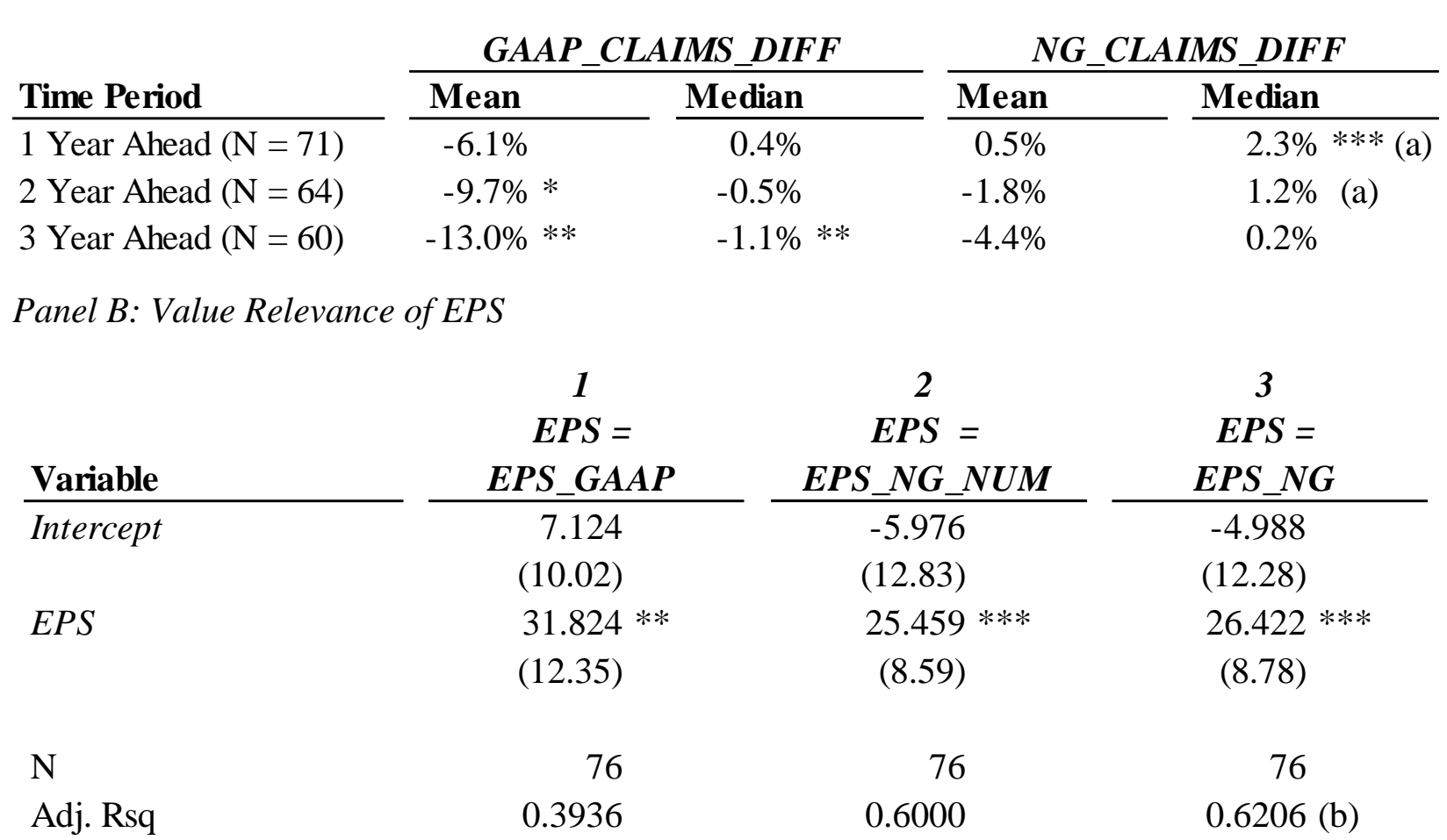

This table presents the results of two tests of whether denominator increasing adjustments are informative. The sample in this table consists of profit-profit firms with denominator increasing adjustments. Panel A presents statistics on the differences between potential claims reflected in denominators and actual future claims, for GAAP $\left(G A A P \_C L A I M S \_D I F F\right)$ and non-GAAP denominators $\left(N G_{-} C L A I M S \_D I F F\right)$. Negative values indicate that a denominator underrepresents new future claims. "(a)" in Panel A denotes that the difference between GAAP_CLAIMS_DIFF and NG_CLAIMS_DIFF is statistically significant at the 5\% level, using two-sample t-tests of means or the Wilcoxon rank-sum test. Panel B presents tests of value relevance for the price per share of common equity, COMMON_PRICE, using three different measures of firms' earnings per share. EPS_GAAP is GAAP diluted EPS. $E P S \_N G \_N U M$ is the numerator of non-GAAP EPS divided by the GAAP diluted EPS denominator. $E P S \_N G$ is non-GAAP EPS as reported by the firm. Coefficient estimates are presented above standard errors, which are presented in parentheses and clustered by firm. "(b)" in Panel B denotes that the difference in the explanatory power of the model in Column 3 and that in Column 2 is statistically significant at the $5 \%$ level, based on the Clarke test. Continuous variables are winsorized at the 1st and 99th percentile. All variables are defined in Appendix 1. *, **, and $* * *$ indicate a statistically significant difference from zero at the $10 \%, 5 \%$, and $1 \%$ level, respectively. 
Table 7: Determinants of No Denominator Adjustment by Loss Converting Firms

Panel A: Descriptive Statistics for Variables in Determinants Model

\begin{tabular}{|c|c|c|c|c|}
\hline Variable & $\mathbf{N}$ & Mean & Median & Std. Dev. \\
\hline NO_DENOM_ADJ & $\overline{350}$ & $\overline{0.44}$ & $\overline{0}$ & 0.50 \\
\hline TRANS_ITEM & 350 & 0.91 & 1 & 0.28 \\
\hline SIZE & 350 & -0.40 & -0.44 & 0.86 \\
\hline$B M$ & 350 & 0.24 & 0.02 & 1.13 \\
\hline STDROA & 350 & 0.29 & -0.12 & 1.15 \\
\hline N_ANALYSTS & 350 & 11.21 & 8.00 & 9.05 \\
\hline LIT_RISK & 350 & 0.15 & 0 & 1.02 \\
\hline$N E G \_F E \_G A A P$ & 350 & 0.72 & 1 & 0.45 \\
\hline$N E G \_F E \_I B E S$ & 350 & 0.32 & 0 & 0.47 \\
\hline
\end{tabular}

This table presents determinants of whether loss converting firms' do not make denominator adjustments, based on a probit model. The sample in this table consists of loss converting firms that either do not adjust the denominator $\left(N O \_D E N O M \_A D J=1\right)$ or else make denominator increasing adjustments $\left(N O \_D E N O M \_A D J=0\right)$. TRANS_ITEM indicates the presence of one-time items in GAAP earnings. $L O G \_A S S E T$ measures firm assets. BM is the book-tomarket ratio. STDROA measures earnings volatility. $N_{-}$ANALYSTS is the number of analysts following the firm. LIT_RISK measures litigation risk. NEG_FE_GAAP indicates whether the firm misses earnings benchmarks on a GAAP basis. NEG_FE_IBES indicates whether the firm misses earnings benchmarks on an $\mathrm{I} / \mathrm{B} / \mathrm{E} / \mathrm{S}$ street basis, comparing I/B/E/S actual street EPS to I/B/E/S forecasted street EPS. Panel A presents descriptive statistics, and Panel B presents the results. In Panel B, coefficient estimates are presented above standard errors, which are presented in parentheses and clustered by firm. Continuous variables have been standardized to be mean zero and have a variance of one. Estimated marginal effects are presented next to coefficients and calculated as an increase in the probability of the dependent variable when the independent variable changes from zero to one while holding all other independent variables at their mean. Continuous variables are winsorized at the 1st and 99th percentile. All variables are defined in Appendix 1. $*, * *$, and $* * *$ indicate a statistically significant difference from zero at the $10 \%, 5 \%$, and $1 \%$ level, respectively. 
Table 7: Determinants of No Denominator Adjustment by Loss Converting Firms (cont.)

Panel B: Determinants Model

\begin{tabular}{|c|c|c|c|c|}
\hline \multirow[b]{2}{*}{ Variable } & \multicolumn{4}{|c|}{ NO_DENOM_ADJ } \\
\hline & \multicolumn{2}{|l|}{ (1) } & \multicolumn{2}{|l|}{$(2)$} \\
\hline \multirow[t]{2}{*}{ Intercept } & -0.096 & & -0.173 & \\
\hline & $(0.30)$ & & $(0.31)$ & \\
\hline \multirow[t]{2}{*}{ TRANS_ITEM } & -0.208 & -0.08 & -0.203 & -0.08 \\
\hline & $(0.26)$ & & $(0.26)$ & \\
\hline \multirow[t]{2}{*}{$S I Z E$} & $0.190 *$ & 0.07 & $0.199 *$ & 0.08 \\
\hline & $(0.10)$ & & $(0.11)$ & \\
\hline \multirow[t]{2}{*}{$B M$} & $0.294 * * *$ & 0.12 & $0.300 * * *$ & 0.12 \\
\hline & $(0.08)$ & & $(0.08)$ & \\
\hline \multirow[t]{2}{*}{ STDROA } & 0.086 & 0.03 & 0.074 & 0.03 \\
\hline & $(0.08)$ & & $(0.08)$ & \\
\hline \multirow[t]{2}{*}{ N_ANALYSTS } & -0.018 & -0.01 & -0.016 & -0.01 \\
\hline & $(0.01)$ & & $(0.01)$ & \\
\hline \multirow[t]{2}{*}{$L I T \_R I S K$} & $-0.155 *$ & -0.06 & $-0.144 *$ & -0.06 \\
\hline & $(0.08)$ & & $(0.08)$ & \\
\hline \multirow[t]{2}{*}{$N E G \_F E \_G A A P$} & $0.430 * *$ & 0.16 & $0.324 *$ & 0.12 \\
\hline & $(0.18)$ & & $(0.18)$ & \\
\hline \multirow[t]{2}{*}{$N E G \_F E \_I B E S$} & & & $0.407 * *$ & 0.16 \\
\hline & & & $(0.16)$ & \\
\hline $\mathrm{N}$ & 350 & & 350 & \\
\hline $\mathrm{N}=1$ & 153 & & 153 & \\
\hline $\mathrm{N}=0$ & 197 & & 197 & \\
\hline $\mathrm{ROC}$ & 0.6971 & & 0.7120 & \\
\hline
\end{tabular}


Table 8: Comparing I/B/E/S Actual Street EPS and Firms' Non-GAAP EPS

Panel A: Univariate Tests

\begin{tabular}{|c|c|c|}
\hline Variable & $\begin{array}{c}1 \\
E X C E E D \\
\text { Mean } \\
\end{array}$ & $\begin{array}{c}1 \\
\begin{array}{c}E X C E E D \_M B \\
\text { Mean }\end{array} \\
\end{array}$ \\
\hline NO_DENOM_ADJ $=1$ & 0.37 & 0.14 \\
\hline$N O \_D E N O M \_A D J=0$ & 0.14 & 0.07 \\
\hline Difference & $0.23 * * *$ & $0.07 * *$ \\
\hline
\end{tabular}

Panel B: Multivariate Tests

$\frac{\text { Variable }}{\text { Intercept }}$

NO_DENOM_ADJ

TRANS_ITEM

RECUR_EXCL

N_ANALYSTS
2

\begin{tabular}{lc}
\multicolumn{2}{c}{$\mathbf{2}$} \\
\multicolumn{2}{c}{$\boldsymbol{E C E E D}$} \\
\hline$-0.972 * *$ \\
$(0.43)$ & \\
$\mathbf{0 . 7 3 9} * * *$ & 0.22 \\
$(0.16)$ & \\
0.164 & 0.05 \\
$(0.24)$ & \\
$0.727 *$ & 0.16 \\
$(0.37)$ & \\
$-0.020 * *$ & -0.01 \\
$(0.01)$ &
\end{tabular}

429

104

325

0.6924
3

EXCEED_MB

$-5.295 * * *$

$(0.35)$

$\mathbf{0 . 4 0 6} * 0.04$

(0.21)

$0.101 \quad 0.01$

(0.33)

$4.548 * * * \quad 0.08$

(0.17)

$-0.045 * * \quad 0.00$

(0.02)

359

34

325

0.7341

This table presents tests of whether firms' non-GAAP EPS is perceived by analysts as being inflated, and whether this perception differs based on denominator adjustments. The sample in this table consists of loss converting firms that either do not adjust the denominator $\left(N O \_D E N O M_{-} A D J=1\right)$ or else make denominator increasing adjustments $\left(N O \_D E N O M \_A D J=0\right) . E X C E E D$ indicates that firms' non-GAAP EPS exceeds, i.e., is more positive than, I/B/E/S actual street EPS. EXCEED_MB indicates that firms' non-GAAP EPS exceeds, i.e., is more positive than, I/B/E/S actual street EPS, and that the firm meets or beats the I/B/E/S street EPS forecast only by exceeding. Panel A presents univariate tests and the results of two-sample t-tests of means. Panel B presents multivariate tests which add controls for the persistence of firms' excluded items (TRANS_ITEM; and RECUR_EXCL, which indicates the exclusion of recurring items when calculating non-GAAP earnings) and the number of analysts following the firm (N_ANALYSTS). In Panel B, coefficient estimates from probit regressions are presented above standard errors, which are presented in parentheses and clustered by firm. Estimated marginal effects are presented next to coefficients and calculated as an increase in the probability of the dependent variable when the independent variable changes from zero to one while holding all other independent variables at their mean. Coefficients of interest are denoted in bold font. Continuous variables are winsorized at the 1 st and 99th percentile. All variables are defined in Appendix 1. *,**, and *** indicate a statistically significant difference from zero at the $10 \%, 5 \%$, and $1 \%$ level, respectively. 
Table 9: How do Loss Converting Firms Increase Denominators?

Panel A: Firms with the Lowest Quartile (Q1) of Stock Price / Average Strike Price

Adjustment

Apply GAAP Calculation to Non-GAAP Profit

Include Claims Different from GAAP Calculation

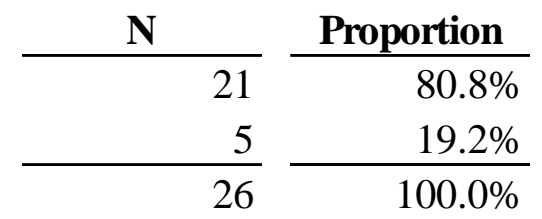

Panel B: Firms with the Second Lowest Quartile (Q2) of Stock Price / Average Strike Price

\begin{tabular}{lrrrr} 
Adjustment & & N & & Proportion \\
\hline Apply GAAP Calculation to Non-GAAP Profit & & 29 & & $96.7 \%$ \\
Include Claims Different from GAAP Calculation & & 1 & $3.3 \%$ \\
& 30 & & $100.0 \%$
\end{tabular}

This table presents statistics from hand-collection to identify the prevalence of loss converting firms including more claims than would be required by applying the GAAP calculation to non-GAAP earnings. For all SBC-only loss converting firms, including those without adjustments, we calculate cutoffs for the first and second quartile of stock price ( $p r c c \_f$ from Compustat) divided by average strike price of outstanding options (optprcey from Compustat). Then, we randomly select up to 30 observations from firms with denominator adjustments within each quartile (only 26 firms in the lowest quartile adjust the denominator). We determine the nature of denominator adjustments by examining the earnings announcement and $10-\mathrm{K}$ for each adjustment. "Apply GAAP Calculation to Non-GAAP Profit" represents firms calculating the denominator of non-GAAP EPS by using non-GAAP profitable earnings in place of the GAAP loss. "Include Claims Different from GAAP Calculation" represents firms adding claims differently from what would be required by applying the GAAP calculation to non-GAAP earnings. 


\section{Table 10: Analysts' Forecast Revisions and Firms' Denominator Adjustments}

Panel A: Descriptive Statistics for Variables in Forecast Revision Model

\begin{tabular}{|c|c|c|c|c|}
\hline Variable & $\mathbf{N}$ & Mean & Median & Std. Dev. \\
\hline REVISION & 2,190 & -0.003 & -0.001 & 0.01 \\
\hline$F E \_N G E P S$ (per share) & 2,190 & 0.01 & 0.02 & 0.39 \\
\hline DENOM_ADJ & 2,190 & 0.138 & 0 & 0.35 \\
\hline$L O G \_M K T C A P$ & 2,190 & 8.004 & 7.912 & 1.60 \\
\hline$L O S S \_C N V R T$ & 2,190 & 0.134 & 0 & 0.34 \\
\hline TRANS_ITEM & 2,190 & 0.882 & 1 & 0.32 \\
\hline
\end{tabular}

This table presents tests of whether how analyst forecast revisions relate to non-GAAP EPS differently when firms make denominator adjustments, following the test in Bhattacharya et al. (2003). The sample in this table consists of all firms in our sample. REVISION measures analysts' revisions of one-year-ahead EPS forecasts after the current year's earnings announcement. FE_NGEPS measures the firm's non-GAAP earnings surprise. DENOM_ADJ indicates that the denominator of non-GAAP EPS differs from that of GAAP diluted EPS. LOG_MKTCAP measures the firm's market cap. LOSS_CNVRT indicates whether the firm is a loss converting firm. TRANS_ITEM indicates the presence of one-time items in GAAP earnings. Panel A presents descriptive statistics, and Panel B presents the results. In Panel B, coefficient estimates are presented above standard errors, which are presented in parentheses and clustered by firm. Coefficients of interest are denoted in bold font. Continuous variables are winsorized at the 1st and 99th percentile. All variables are defined in Appendix $1 . *, *$, and $* * *$ indicate a statistically significant difference from zero at the $10 \%, 5 \%$, and $1 \%$ level, respectively. 
Table 10: Analysts' Forecast Revisions and Firms' Denominator Adjustments (cont.)

Panel B: Forecast Revision Model

\begin{tabular}{|c|c|c|c|}
\hline \multirow[b]{2}{*}{ Variable } & \multicolumn{3}{|c|}{ REVISION } \\
\hline & $(1)$ & $(2)$ & (3) \\
\hline \multirow[t]{2}{*}{ Intercept } & $-0.004 * * *$ & $-0.004 * * *$ & $-0.016 * * *$ \\
\hline & $(0.00)$ & $(0.00)$ & $(0.00)$ \\
\hline \multirow[t]{2}{*}{$F E \_N G E P S$} & $0.097 * *$ & 0.083 & 0.210 \\
\hline & $(0.05)$ & $(0.05)$ & $(0.23)$ \\
\hline \multirow[t]{2}{*}{$F E \_N G E P S \times D E N O M \_A D J$} & & 0.075 & $0.176 *$ \\
\hline & & $(0.11)$ & $(0.11)$ \\
\hline \multirow[t]{2}{*}{ DENOM_ADJ } & & 0.000 & 0.001 \\
\hline & & $(0.00)$ & $(0.00)$ \\
\hline \multirow[t]{2}{*}{$F E \_N G E P S \times L O G \_M K T C A P$} & & & -0.024 \\
\hline & & & $(0.03)$ \\
\hline \multirow[t]{2}{*}{$F E \_N G E P S \times L O S S \_C N V R T$} & & & $-0.278 * *$ \\
\hline & & & $(0.12)$ \\
\hline \multirow[t]{2}{*}{$F E \_N G E P S \times T R A N S \_I T E M$} & & & 0.092 \\
\hline & & & $(0.14)$ \\
\hline \multirow[t]{2}{*}{$L O G \_M K T C A P$} & & & $0.001 * * *$ \\
\hline & & & $(0.00)$ \\
\hline \multirow[t]{2}{*}{$L O S S \_C N V R T$} & & & 0.000 \\
\hline & & & $(0.00)$ \\
\hline \multirow[t]{2}{*}{ TRANS_ITEM } & & & 0.001 \\
\hline & & & $(0.00)$ \\
\hline $\mathrm{N}$ & 2,190 & 2,190 & 2,190 \\
\hline Adj. Rsq. & 0.0124 & 0.0129 & 0.0540 \\
\hline
\end{tabular}

